\title{
Graphene Oxide and Stabilized Ortho-Silicic Acid as Modifiers of Amnion and Burn Affected Skin: A Comparative Study
}

This article was published in the following Dove Press journal: Nanotechnology, Science and Applications

\author{
Anna Pielesz' \\ Janusz Fabia' \\ Włodzimierz Biniaśl \\ Ryszard Fryczkowski (D) \\ Beata Fryczkowska (iD) \\ Andrzej Gawłowski' \\ Alicja Machnicka ${ }^{2}$ \\ Rafał Bobiński (iD) \\ Henk-Maarten Laane ${ }^{4}$ \\ Wioletta Waksmańska (iD ${ }^{5}$ \\ 'Faculty of Materials, Civil and \\ Environmental Engineering, University of \\ Bielsko-Biala, Bielsko-Biala, Poland; \\ ${ }^{2}$ Department of Microbiology and \\ Environmental Technology, Institute of \\ Engineering and Environmental \\ Protection, University of Bielsko-Biała, \\ Bielsko-Biala, Poland; ${ }^{3}$ Faculty of Health \\ Sciences, Department of Biochemistry \\ and Molecular Biology, University of \\ Bielsko-Biala, Bielsko-Biala, Poland; \\ ${ }^{4}$ ReXil Agro BV, Hengelo, OV, The \\ Netherlands; ${ }^{5}$ Faculty of Health Sciences, \\ Department of Public Health, University \\ of Bielsko-Biala, Bielsko-Biala, Poland
}

\begin{abstract}
Introduction: Oxidative tissue damage caused by reactive oxygen species results in a significant decrease in the total antioxidant capacity of the biological system. The aim of this interdisciplinary study was to answer the question of whether active antioxidants modify, at a molecular and supramolecular level, the tissue of pathological amnion and the necrotic eschar degraded in thermal burn.
\end{abstract}

Methods: A Nicolet 6700 Fourier-transform spectrophotometer with OMNIC software and the EasiDiff diffusion accessory were used in the FTIR spectroscopic analysis. A NICOLET MAGNA-IR 860 spectrometer with FT-Raman accessory was used to record the Raman spectra of the samples. The samples were exposed to bacteria capable of causing nosocomial infections, ie Gram-positive Staphylococcus aureus and Gram-negative Escherichia coli and Pseudomonas aeruginosa. Whereas samples of hypotrophic amnion interacted with Staphylococcus aureus, Escherichia coli and Enterococcus faecalis. The obtained flame retardant effect of placentas was evaluated using the method of the limiting oxygen index (LOI).

Results: The infrared spectroscopy analysis proved that after modification of the amniotic samples in graphene oxide and ortho-silicic acid, the amide II band is split into two components. Incubation of samples in modifier solutions: graphene oxide, sodium ascorbate and L-ascorbic acid results in shifts and changes of intensity within the broadly understood lipid band 1743-1745-1747 $\mathrm{cm}^{-1}$. The oxidising changes observed within the lipid and amide bands are affected by the incubation effect of graphene oxide as a modifier, possibly adsorbing on the surface of the amniotic membrane. On the basis of microbiological studies, pathogenic bacteria commonly causing amniotic infections and growing in burn wounds were found to have particularly good resistance to stabilized ortho-silicic acid (E. coli) and lactoferrin (S.aureus)

Conclusion: This thermogravimetric study found the highest stability of the analysed tissues (hypotrophic amnion and burnt epidermis) after modification with graphene oxide and sodium ascorbate.

Keywords: graphene oxide, stabilized ortho-silicic acid, sodium ascorbate, L-ascorbic acid

\section{Introduction}

Local and general body response to thermal burn is a complex issue. Thermal burn not only leads to damage of the skin but also to deep and long-lasting changes in body metabolism, defined as the so-called oxidative stress. Oxidative tissue damage caused by reactive oxygen species also results in a significant decrease in the total antioxidant capacity of the biological system. Tissue is modified, therefore the search for markers of
Correspondence: Anna Pielesz

University of Bielsko-Biala, ul. Willowa 2,

Bielsko-Biala, 43-309, Poland

Tel +48338279114

Fax +48338279355

Email apielesz@ath.bielsko.pl
Nanotechnology, Science and Applications 2021:14 49-67 
chemical alteration within molecular studies is also helpful in diagnosing degenerative diseases (eg connective tissue diseases, burns, difficult wounds and pregnancy pathology). Antioxidant intervention will significantly help restore cellular immunity, reduce damage caused by free radicals and minimize tissue destruction resulting from burns, ${ }^{1-4}$ as well as restore the process of exchange of bioactive agents in hypotrophic amnion samples. The pathology called intrauterine hypotrophy is generally a pregnancy complication consisting in giving birth to a child with low birth weight. Structurally, the very process of occurrence of the above pathology is correlated with a disorder of the collagen synthesis process and as such can be successfully analysed by spectroscopic methods. The three-layer molecular structure of the amnion contains fibrous and non-fibrous I, II, III and V collagens, as well as glycoproteins and proteoglycans. Such a structure is conducive to the processes of exchange of macromolecules and bioactive agents, which, after being joined to the amnion, may fulfil antiseptic, regenerative and blood vessel formation function, and may modify proteins. ${ }^{5}$ In the study of correction processes of damaged tissue, the search for new active antioxidants such as AA (L-ascorbic acid) or SA (sodium ascorbate $)^{6,7}$ as well as new modifiers of damaged tissue, eg orthosilicic acid ${ }^{8-11}$ or graphene and graphene oxide, ${ }^{12}$ plays an important role. The studies tend to have an interdisciplinary aspect. It is worth mentioning that while FTIR (Fouriertransform infrared spectrometry) and FTR (Fourier-transform raman spectrometry) studies are the primary source of information on the molecular structure of biopolymer, changes in collagen structure at the supramolecular level ${ }^{10,11,13,14}$ are assessed on the basis of the results of small-angle X-ray scattering (SAXS) and - indirectly - thermogravimetric analysis (TGA). Limiting oxygen index (LOI) is indirectly a source of information on the conditions of thermal oxidative stress in protein $^{15}$ and it macroscopically assesses the effectiveness of the antioxidants used for treatment. In the case of analysing biological material in the form of tissues, a necessary complement of structural studies are microbiological analyses ${ }^{16,17}$ using reference strains of the following bacteria: Escherichia coli, Staphylococcus aureus, Pseudomonas aeruginosa and Enterococcus faecalis. Staphylococcus aureus is one of the most important bacterial pathogens in humans, it colonizes the skin and mucous membranes and is the cause of many diseases. The increased risk of staphylococcal infection affects patients after surgery, with burn wounds, as well as with implanted biomaterials.

Pseudomonas aeruginosa is a very important etiological factor in nosocomial infections which can sometimes be fatal. $P$. aeruginosa is responsible for causing skin and soft tissue infections, acute and chronic infections, for instance in oncological patients, patients after transplantation or patients with burn wounds. The bacteria cause diseases associated with toxins and enzymes which they produce, which may slow down the immune response of the host (inhibiting phagocytosis, damage to macrophages or inactivation of the IgG and IgA immunoglobulins), damage or destroy cells and tissues of the infected organism or even weaken the natural microflora of the host. ${ }^{13,14,18,19}$ From a clinical and epidemiological point of view, Escherichia coli, a frequent etiological factor associated with burn wounds, is a very important species. Rich in nutritional substances, the wet environment of a chronic wound constitutes ideal environment for its development. Enterococcus faecalis bacteria are typical opportunistic pathogens which may cause severe nosocomial infections. Enterococcus faecium and Enterococcus faecalis are clinically relevant and they are responsible for more than 90\% of all infections. ${ }^{15,20}$ Enterococcus faecalis - alongside Escherichia coli, staphylococci and beta-hemolytic streptococci - causes non-specific infection of amniotic cavity, the so-called amniotic infection syndrome.

The aim of this interdisciplinary study, which involved Fourier-transform infrared spectrometry (FTIR), Fourier-transform raman spectrometry (FTR), thermogravimetric analysis (TGA), Limiting oxygen index analysis (LOI) and microbiology, was to answer the question of whether the following active antioxidants: ortho/oligomeric silicic acid (OSA), graphene oxide (GO), sodium ascorbate (SA), L-ascorbic acid (AA), orthosilicic acid $\left(\mathrm{H}_{4} \mathrm{SiO}_{4}\right)$, lactoferrin (LF) modify, at a molecular and supramolecular level, the tissue of pathological amnion and the necrotic eschar degraded in thermal burn. The intention of the authors, apart from examining the phenomenon, was to select such concentrations and composition of the solutions of modifiers which could become innovative modifiers used in transplants (amnion) and enhance regeneration of epidermis degraded in thermal burn.

\section{Materials and Methods}

Abbreviations: allogenic unburned full-thickness skin $=$ human skin samples (SP); human burn wound full-thickness skin; human burn skin (15S, 21S); human burn skin in the presence of ortho/oligomeric silicic acid OSA (15S6-a dilution factor $1: 6000 ; 15 \mathrm{~S} 10$-a dilution factor $1: 10,000)$; human burn skin incubated in the presence of graphene oxide (21S GO); human burn skin heated to the 
temperature of 21S (21S 193); human burn skin in the presence of OSA (a dilution factor between 1:6000 or $1: 10,000)$ heated to the temperature of $193^{\circ} \mathrm{C}(21 \mathrm{~S} 6193$, 21S10 193); amniotic samples: BS and IW in the presence of OSA, GO, SA, AA, $\mathrm{H}_{4} \mathrm{SiO}_{4}$, lactoferrin.

\section{Chemicals and Materials}

The following materials and reagents were used in the examination: solutions with a content of $0.001 \mathrm{~g}$ of the following chemical compounds: ortho/oligomeric silicic acid OSA, graphene oxide $\mathrm{GO}$, sodium ascorbate SA, L-ascorbic acid AA, silicic acid $\mathrm{H}_{4} \mathrm{SiO}_{4}$, lactoferrin. Stabilized non-colloidal silicic acid OSA (a dilution factor between $1: 6000$ and $1: 10,000)$ is made according to patented production processes in which polymerization is prevented. $^{8}$

\section{Sampling Procedure}

Two types of tissues were analysed in this study: hypotrophic (BS and IW) amnion and samples of epidermis after thermal injury (21S and $15 \mathrm{~S}$ ). Comparative analyses of the impact of incubation on amnion tissue (BS and IW in the presence of OSA, GO, SA, AA, $\mathrm{H}_{4} \mathrm{SiO}_{4}$, lactoferrin) and the burn skin (21S and $15 \mathrm{~S}$ in the presence of OSA) in the presence of the modifiers were also performed.

Two types of epidermis degraded in thermal injury and coming from demarcation were analysed: sample 15S: 15\% TBSA, 5\% III/IV (flame burn), demarcation of necrosis of a 31-year-old man's arm; sample 21S: 3\% TBSA, including $2 \%$ III/IV (heat source burn), demarcation of necrosis of a 26-year-old woman's forearm.

Biopsy material was obtained as a result of necrosis resection and placed in $0.9 \%$ saline, and stored in a freezer for further studies. Application of the ortho-silicic acid OSA solutions (1:6000) was performed on biopsies. The samples (fragments of skin or amniotic samples) had been incubated at $20^{\circ} \mathrm{C}$ for 5 days in modifier solutions. Clean amnion, without amniotic fluid or adherent tissues, was placed in a sterile container. The sample was frozen $\left(-20^{\circ}\right.$ C) and transported to the laboratory in a portable freezer. The material was placed in $0.9 \%$ saline and stored in the freezer for further examination. The measurements were performed integrally from the samples (fragments of skin or amniotic samples).

\section{Spectroscopic Analysis}

A Nicolet 6700 Fourier-transform spectrophotometer (Thermo Scientific, USA) with OMNIC 7.3 software and the EasiDiff diffusion accessory (Thermo Nicolet Industries) were used in the FTIR spectroscopic analysis. The subject of spectral analysis was dry solid samples (skin samples and amnion samples). The samples of the above-mentioned dry tissues had been prepared by drying in a laboratory dryer at $35 \mathrm{C}$ for three days. The spectral region was 4000-500 $\mathrm{cm}^{-1}$, resolution: $4 \mathrm{~cm}^{-1}$ and the number of scans involved 128 of the solid samples.

A NICOLET MAGNA-IR 860 spectrometer with FTRaman accessory was used to record the Raman spectra of the samples. The solid samples were then irradiated with a $1064 \mathrm{~nm}$ line YAG laser and scattered radiation was collected with $4 \mathrm{~cm}^{-1}$ resolution.

During the examination, spectra of three repacked samples of each individual sample were averaged to one spectrum. All the spectra were obtained using a linear baseline and pre-processed with Fourier smoothing (Grams 32 AI software, Galactic Industries; smoothing degree, $50 \%$ ).

\section{Microbiological Analysis}

Reference strains of the Escherichia coli, Staphylococcus aureus, Pseudomonas aeruginosa and Enterococcus faecalis bacteria purchased from American Type Culture Collection (ATCC) were used in the microbiological study. Samples of amnion and burn human skin were used in the microbiological analyses. The samples were exposed to bacteria capable of causing nosocomial infections, ie Gram-positive Staphylococcus aureus and Gramnegative Escherichia coli and Pseudomonas aeruginosa. Whereas samples of hypotrophic amnion interacted with Staphylococcus aureus, Escherichia coli and Enterococcus faecalis. For the development of micro-organisms, the following culture media were used: mannitol salt agar $S$. aureus, MacConkey agar - E. coli, selective substrate for the isolation of $P$. aeruginosa and Slanetz and Bartley agar - Enterococcus faecalis. After incubation, the grown colonies (S. aureus, E. coli, P. aeruginosa and E. faecalis) were washed off with sterile physiological saline. Next, a bacterial suspension of $9 \cdot 10^{8}$ of cells per $1 \mathrm{~cm}^{3}$ according to the McFarland 3 standard was prepared. S. aureus, E. coli, $P$. aeruginosa and E. faecalis suspensions with a volume of $0.1 \mathrm{~cm}^{3}$ were applied to agar by the surface inoculation method in accordance with the procedure. Amnion and burn human skin samples of $1 \mathrm{~cm}^{2}$ areas were applied to the prepared plates. All the samples of organic material were incubated for 6 days in solutions of the following modifiers: OSA, GO, SA, AA, $\mathrm{H}_{4} \mathrm{SiO}_{4}, \mathrm{LF}$. 
The solutions for the sample incubation contained $0.001 \mathrm{~g}$ of the above modifiers. The test material (samples of amnion and burn skin) was incubated for 24 hours at the temperature of $36 \pm 2^{\circ} \mathrm{C}$. After the process of cultivation, growth inhibition zones of the bacteria used in the test were read off around the tested samples of amnion and burn skin.

\section{LOI}

The obtained flame retardant effect of placentas was evaluated using the method of the limiting oxygen index (LOI). The parameter which characterizes the method is the lowest percentage of oxygen in the mixture with nitrogen, at which the test specimen ignites and burns on its own. The measurements were performed in accordance with the PN-ISO 4589 standard.

\section{Thermogravimetric Analyses}

Investigation was performed using a TA Instruments Q500 Thermogravimetric Analyzer. Measurements were performed in a temperature range from $30^{\circ} \mathrm{C}$ to $800^{\circ} \mathrm{C}$ with a heating rate of $20 \mathrm{deg} / \mathrm{min}$ under nitrogen atmosphere (flow rate $60 \mathrm{~cm}^{3} / \mathrm{min}$ ). At a temperature of $800^{\circ}$ $\mathrm{C}$, the inert gas was switched to air for burning the organic remnants of the sample. The data were evaluated by means of the Universal V4.5A (TA Instruments) software.

\section{Ethics}

In general, the analysis involved samples of burn skin or amniotic membrane collected directly from patients after obtaining approval of the Bioethics Committee of the Beskid Medical Chamber in Bielsko-Biala No 2015/12/ 03/1 (burned skin) and 2016/02/11/4 (amniotic membranes and placenta). In each of the above-mentioned procedures, the Bioethics Committee analyzed the following documents: 1. Researcher's conclusion; 2. List of centers participating in the study; 3. Study protocol; 4. Scientific achievements of the research coordinator and principal researchers; 5. Researchers' biography; 6. The patient's informed consent to participate in the study; 7 . Information for the patient; 8. Management of approvals to conduct the research.

All participants gave informed consent to take part in the research, which is in accordance with the Helsinki Declaration.

\section{Results}

\section{FTIR and FTR Spectroscopic Analysis}

Applied in different concentrations to the samples of epidermis degraded in burn, Orthosilicic acid solutions $\left(\mathrm{H}_{4}\right.$ $\mathrm{SiO}_{4} \times \mathrm{nH}_{2} \mathrm{O}$ ) cause a number of changes at the molecular level.

Incubation of the necrotic epidermis tissues for the sample $21 \mathrm{~S}$ in OSA (21S6 and 21S10 Figure 1) causes shifts within the range of amid I-III bands (21S 1693, 1580, $1467 \mathrm{~cm}^{-1} 21 \mathrm{~S} 6169515781468 \mathrm{~cm}^{-1} 21 \mathrm{~S} 10$ $169315731470 \mathrm{~cm}^{-1}$ ). The largest shifts towards lower wavenumbers were observed for amide II, when incubated in the OSA acid at a concentration of 1:10,000.

The bands near 1737, 1743 and $1750 \mathrm{~cm}^{-1}$ are associated with vibrations of ester groups in cell membrane phospholipids [1-2], whereas a small uplift within the $1725 \mathrm{~cm}^{-1}$ band refers to hydrogen bonds around the carbonyl group of lipids (Figure 1). For 21S samples, lipid bands are observed in the area of $1792-1735 \mathrm{~cm}^{-1}$, the exact location of the bands, their height, surface and width is visible after dividing them into components (Figure 2 and Table 1). Heating the $21 \mathrm{~S}$ sample to $193^{\circ} \mathrm{C}$ shifts to lower frequencies and significantly expands the lipid ester band and carbonyl band, it also shifts amide I-II to lower wavenumbers $\left(21 \mathrm{~S} 1693,1580 \mathrm{~cm}^{-1} 21 \mathrm{~S} 193\right.$ $1689,1578 \mathrm{~cm}^{-1}$ ).

A vivid manifestation of the lipid band $1750 \mathrm{~cm}^{-1}$ is observed for the sample modified with OSA 1:6000 (21S6). For the sample 21S6, the band disappears after heating to $193^{\circ} \mathrm{C}$. Whereas during incubation of the epidermis degraded in burn in the solution of 1:10,000 OSA (21S10), a wide band is isolated (Figure 1). In the case of

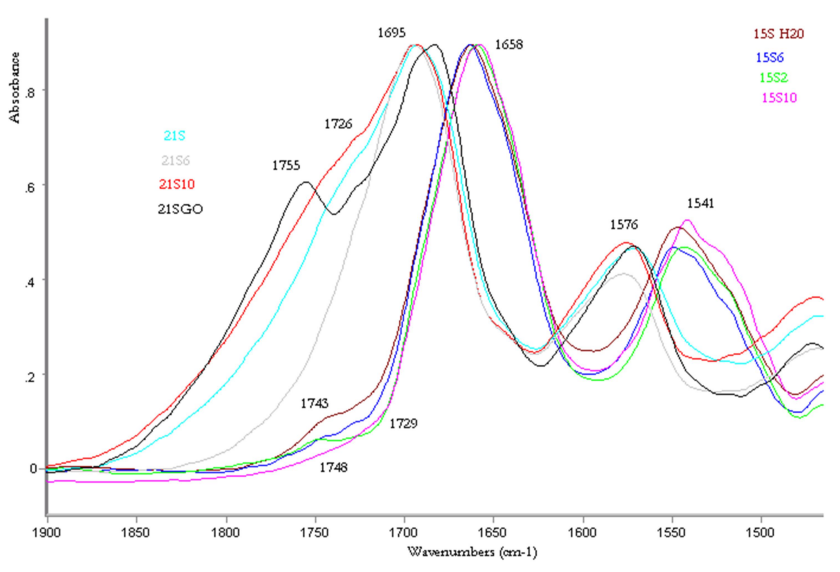

Figure I Fragment of FTIR spectra $\left(1900-1500 \mathrm{~cm}^{-1}\right)$ : a) human burn skin (2IS, I5S); human burn skin in presence of the following modifiers: OSA, GO (I5SI0; I5S2, I5SI0; 2IS6, 2ISI0, 2IS6, 2ISGO). 

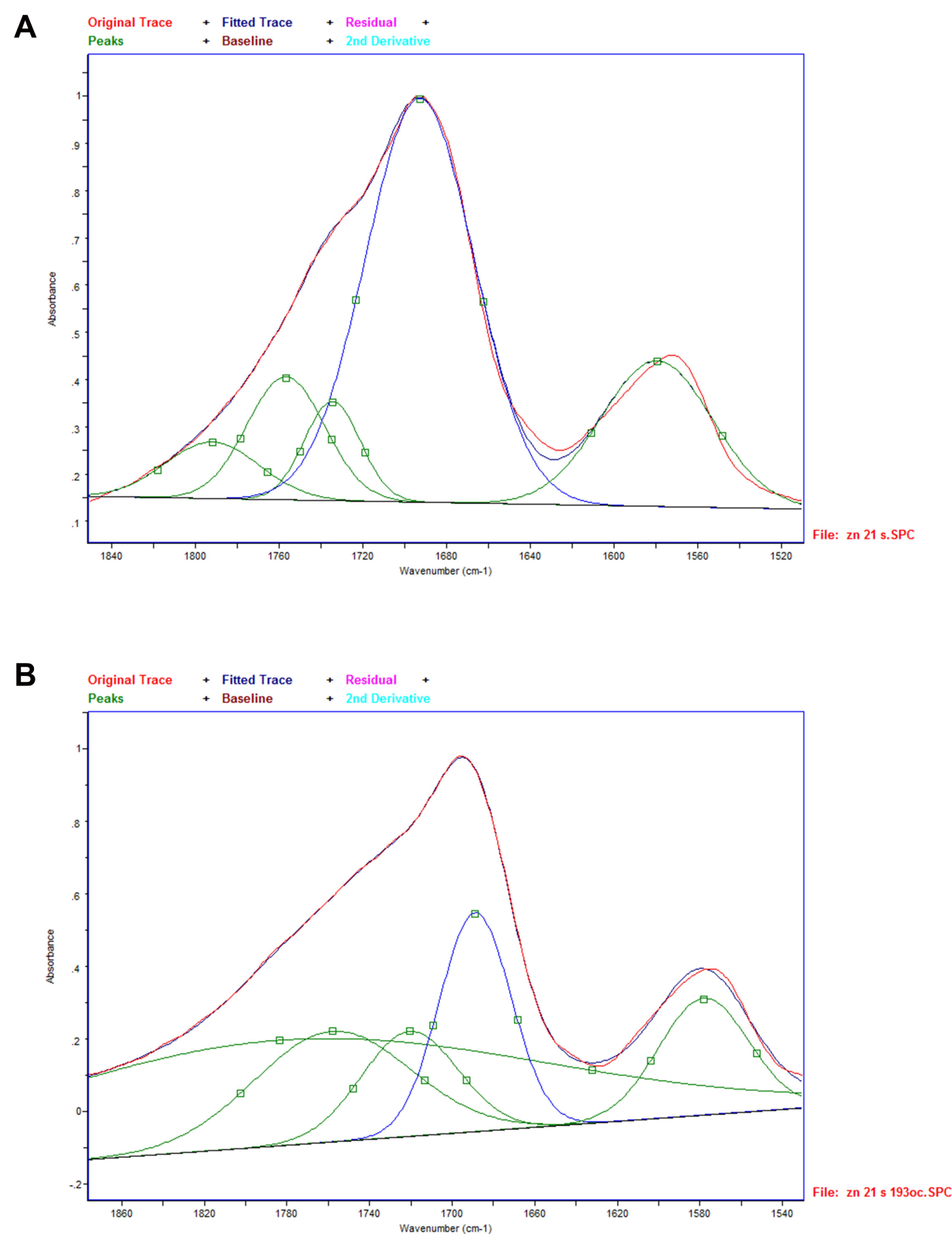

Figure 2 (A and B) Examples of the IR spectrum resolved into Gaussian-shaped bands at around $1750-1500 \mathrm{~cm}^{-1}$ attributed to lipid bands of the samples of human burn 2 IS (A) and human burn skin heated up to $193^{\circ} \mathrm{C}(21 \mathrm{~S} \mathrm{193,} \mathrm{B)}$.

the lipid band for the sample 21S10, no apparent inflection similar to the one for the 21S6 sample is observed, probably due to the shift of the band towards lower wavenumbers and resulting formation of one wider band together with the amide band.

For the $15 \mathrm{~S} 10$ sample - selected for comparative testing - which was modified with OSA 1:10,000 acid and heated successively at the following temperatures: $122^{\circ} \mathrm{C}$ (the appearance of the lipid band $1732 \mathrm{~cm}^{-1}$ ), $191^{\circ} \mathrm{C}$ (shifts within the lipid band $1732 \mathrm{~cm}^{-1}$ ) and $222^{\circ} \mathrm{C}$ (the appearance of the lipid band $1778 \mathrm{~cm}^{-1}$ ) and $256^{\circ} \mathrm{C}$, shifts within the broadly defined lipid band are observed (Figure 3). Heating the sample to $222^{\circ} \mathrm{C}$ and $256^{\circ} \mathrm{C}$ activates interactions within the amide III area, as well as the area characteristic of nucleic acids and characteristic of Si-O-Si stretching vibration band at $1085 \mathrm{~cm}^{-1} .8$

Raman spectrum analysis indicates its activation after the sample has been heated to a temperature of $222^{\circ} \mathrm{C}$ of the hydrogen bond area of approximately $3342 \mathrm{~cm}^{-1}$ and of the amide II-III area, ie an area particularly active in 
Table I Analysis of Resolved into Gaussian-Shaped Lipid Bands

\begin{tabular}{|l|l|l|l|l|}
\hline Samples & Center $\left(\mathbf{c m}^{-1}\right)$ & Height & Area & Width \\
\hline 2 IS & 1792 & 0.12 & 52.68 & 6.67 \\
& 1757 & 0.26 & 43.71 & 12.09 \\
& 1735 & 0.21 & 31.51 & 7.03 \\
& 1693 & 0.85 & 60.98 & 55.42 \\
& 1580 & 0.31 & 62.53 & 20.40 \\
\hline \multirow{2}{*}{2 IS 193 } & 1784 & 0.29 & 303.02 & 69.91 \\
& 1758 & 0.31 & 89.10 & 29.07 \\
& 1721 & 0.29 & 55.21 & 17.08 \\
& 1689 & 0.60 & 40.93 & 26.27 \\
& 1578 & 0.32 & 51.33 & 17.36 \\
\hline
\end{tabular}

oxidation-reduction reactions. Such reactions were characterized in the authors' previous study ${ }^{6}$ (Figure 4).

In the case of the samples of skin degraded in the burn, which were incubated in a solution of graphene oxide 21SGO, a relatively intense lipid band of $1754 \mathrm{~cm}^{-1}$ appears. This band is shifted to lower wavenumbers of $1749 \mathrm{~cm}^{-1}$ for the sample $21 \mathrm{SGO} 193$ heated to $193^{\circ} \mathrm{C}$. The band intensity for the sample 21SGO193 is also reduced, as is visible when the spectrum is divided into components (Figure 5 and Table 2). Incubation of the necrotic epidermis tissues for the sample $21 \mathrm{~S}$ in GO (Figure 5) causes shifts within the range of amid I-II bands (21S 1693, $1580 \mathrm{~cm}^{-1}$ 21SGO $16881579 \mathrm{~cm}^{-1}$ 21SGO193 $16881575 \mathrm{~cm}^{-1}$ ).

Subsequently, the subject of the FTIR spectroscopic analysis was a series of BS amniotic samples. Incubation of the BS amniotic samples in all modifiers in question (except for lactoferrin) causes shifts of amid I-II bands to lower wavenumber values and amid III to higher wavenumber values (Figure 6). For unmodified BS amniotic samples, a lipid band is observed at a wavenumber of $1746 \mathrm{~cm}^{-1}$; the position of this band and its intensity change during incubation in modifier solutions, whereby the most obvious changes in the lipid band are observed for the following samples: OSA and $\mathrm{H}_{4}$ $\mathrm{SiO}_{4} 1737 \mathrm{~cm}^{-1}$ AA $1741 \mathrm{~cm}^{-1}$ and GO $1754 \mathrm{~cm}^{-1}$ (Figure 6). For the samples: BS GO, $\mathrm{BS} \mathrm{H}_{4} \mathrm{SiO}_{4}$ and $\mathrm{BS}$ lactoferrin, the exact location of the bands, their height, surface and width is visible after dividing them into components (Figure 7 and Table 3). The mathematical division of spectra revealed that after modification of the amniotic samples in $\mathrm{GO}$ and $\mathrm{OSA}$ and $\mathrm{H}_{4} \mathrm{SiO}_{4}$, the amide II band is split into two components (1592 and $1557 \mathrm{~cm}^{-1}$ for GO; 1593 and $1557 \mathrm{~cm}^{-1}$ for OSA; 1591 and $1559 \mathrm{~cm}^{-1}$ for $\mathrm{H}_{4} \mathrm{SiO}_{4}$ ). Thus, the amide II area (as for the previously described sample 15S10) is activated during the incubation of amnion in the modifiers of the amide II area, ie an area particularly active in oxidation-reduction reactions ${ }^{6}$ (Figure 7).

\section{Thermogravimetric Study}

The subject of the thermogravimetric analysis included two types of samples of skin degraded in thermal injury: $21 \mathrm{~S}$ and 15S. The curves shown in Figure 8A do not start at a single point, despite the application of the same temperature programme in all measurements. While being conditioned at $30^{\circ} \mathrm{C}$ for 10 minutes, sample $15 \mathrm{~S} 6$ (burn skin incubated in OSA 1:6000) probably lost more water than the others. Conditioning is carried out in order to remove traces of oxygen from the air - the thermobalance chamber is then purged with nitrogen to avoid thermooxidation effects during measurements. The most varied course (also on the FTIR spectrum, Figure 8B) - at lower temperatures (up to $300^{\circ}$ ), visible especially on the DTG curve, was observed in the skin 15S10 (pink lines) and therefore became the object of further examination with heating to the temperatures corresponding to subsequent transformations. The sample $15 \mathrm{~S} 10$, heated up to $300^{\circ} \mathrm{C}$, can also be characterised by the highest changeability in the IR spectrum (Figure 3) in the scope of broadly defined lipid band of amide II-III and stretching vibration band at $1085 \mathrm{~cm}^{-1}$ whereas when heated up to a temperature of $222^{\circ} \mathrm{C}$, the sample is characterised by the highest changeability in the IR spectrum (Figure 4) of the hydrogen bond area of approximately $3342 \mathrm{~cm}^{-1}$ and of the amide II-III area, ie an area particularly active in oxidation-reduction reactions. The degraded epidermis $15 \mathrm{~S} 10$, examined by the above FTIR and FTR spectroscopic methods (Figures 3 and 4), was also selected for comparative studies with the $21 \mathrm{~S}$ series samples.

By analysing the data presented in Figure 9A, it was generally concluded that for the $21 \mathrm{~S}$ series skin samples the nature of transformations up to circa $220^{\circ} \mathrm{C}$ is different compared to the comparative $15 \mathrm{~S} 10$ skin (DTG curves for the $21 \mathrm{~S}$ series show only one maximum at a temperature of about $193^{\circ} \mathrm{C}$ ). The transformations mentioned above (shown in detail on the magnification) seem to refer mainly to the loss of water contained in the tested biological material (which may be differently bound) and correspond to $9.1-10.7 \%$ of the weight loss of the given samples (Table 4).

Transformation of thermal dissociation of organic material, corresponding to the largest loss in sample weight, occurring in the temperature range $220-550^{\circ} \mathrm{C}$ 


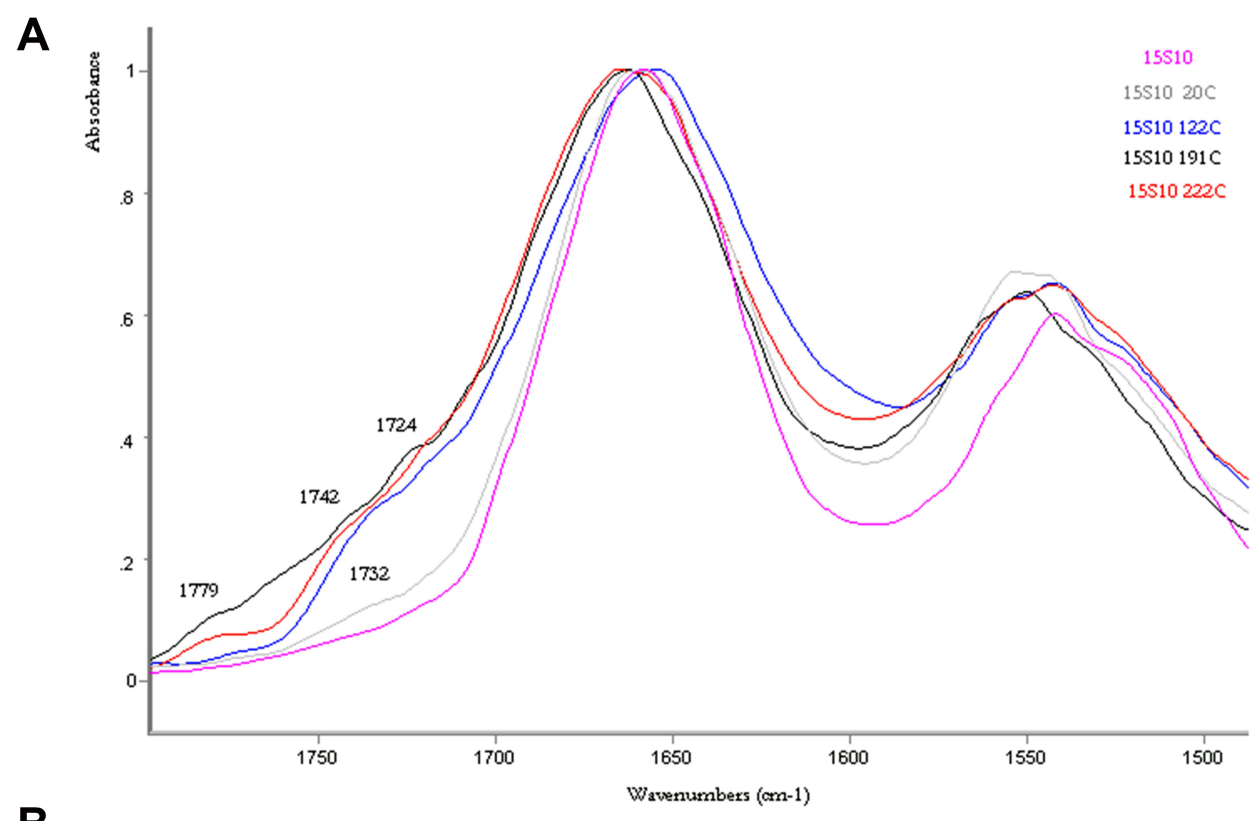

B

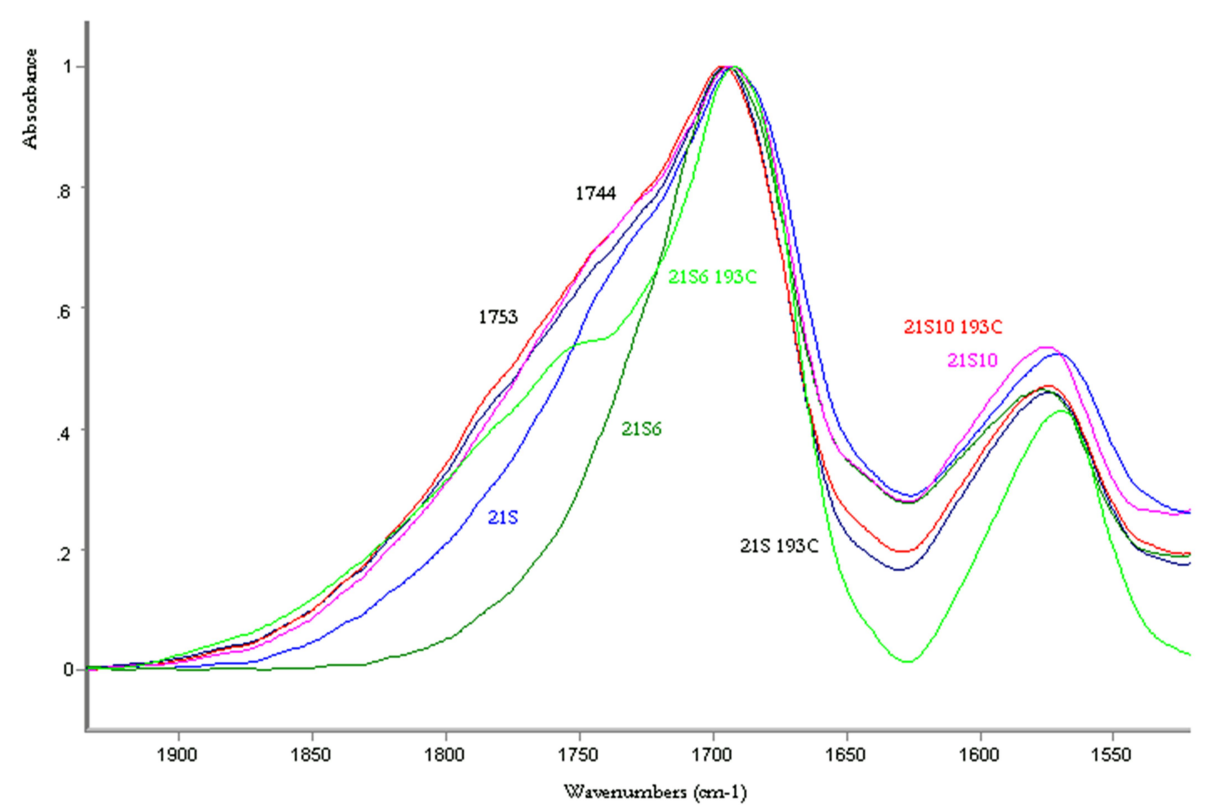

Figure 3 Fragment of FTIR spectra $\left(1900-1500 \mathrm{~cm}^{-1}\right)$ : human burn skin (I5S I0) and human burn skin in presence of OSA, heated up to the temperature range: $20-256^{\circ} \mathrm{C}$ (A); human burn skin (2IS); human burn skin in presence of OSA (2ISI0, 2IS6), heated up to the temperature of $193^{\circ} \mathrm{C}$ (B).

(max. 67.7\%) is single-stage in the case of the 21S skin series samples and multi-stage in the case of the $15 \mathrm{~S} 10$ series. All samples of the tested material incubated in OSA acid or graphene oxide show a significant weight loss above $550^{\circ} \mathrm{C}$ corresponding to the high-temperature transformation of these compounds. The 21S GO sample (skin modified with graphene oxide) has the greatest stability (Figure 9A - enlargement). The beginning of the essential stage of thermal dissociation (degradation) of the organic material corresponding to a minimum on the DTG curve is shifted in this case by $24.4^{\circ} \mathrm{C}$ compared to the nonmodified $21 \mathrm{~S}$ skin sample.

Subsequently, the subject of the thermogravimetric analysis was a series of BS amniotic samples. Having analysed the study results presented in Figure 10, it was generally concluded that the thermal characteristics of the BS series amnion are basically analogous to the characteristics of the $21 \mathrm{~S}$ skin samples. An enlarged fragment of the DTG curves presented on the figure illustrating the first stage of the weight loss of the tested samples, connected mainly with the loss of water contained in 
A

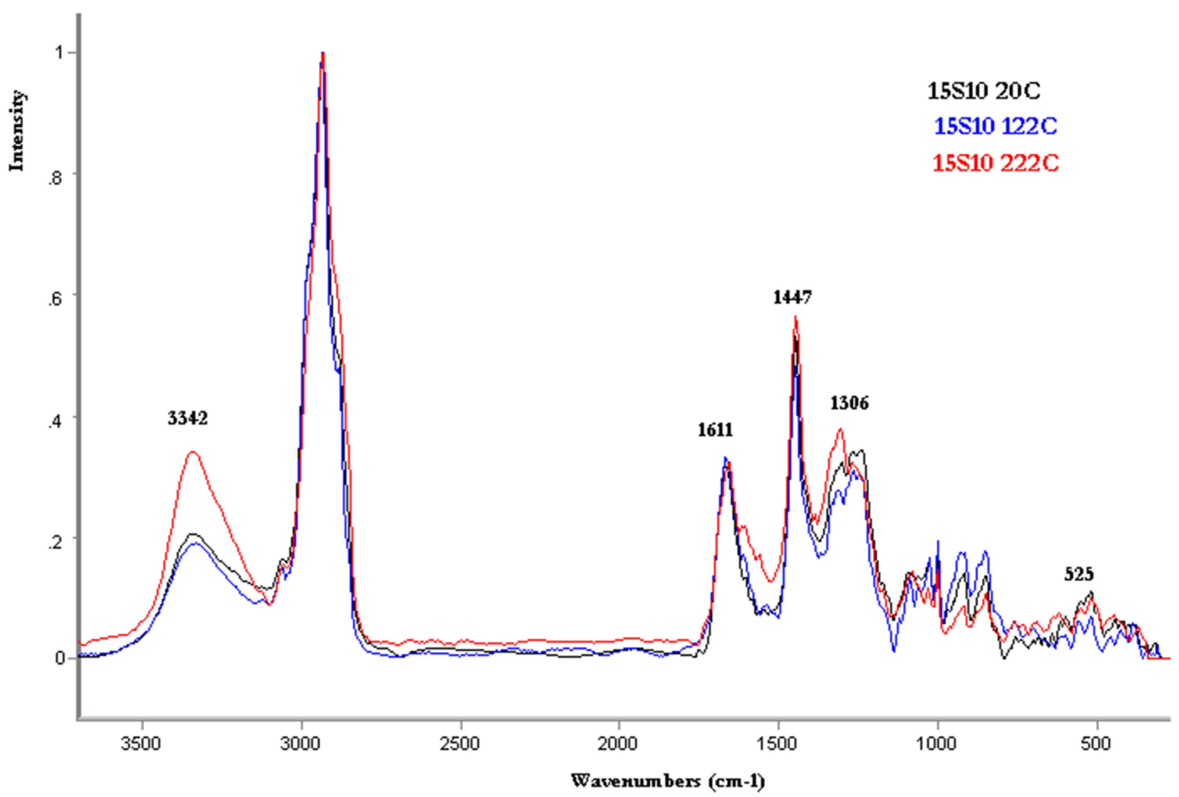

B

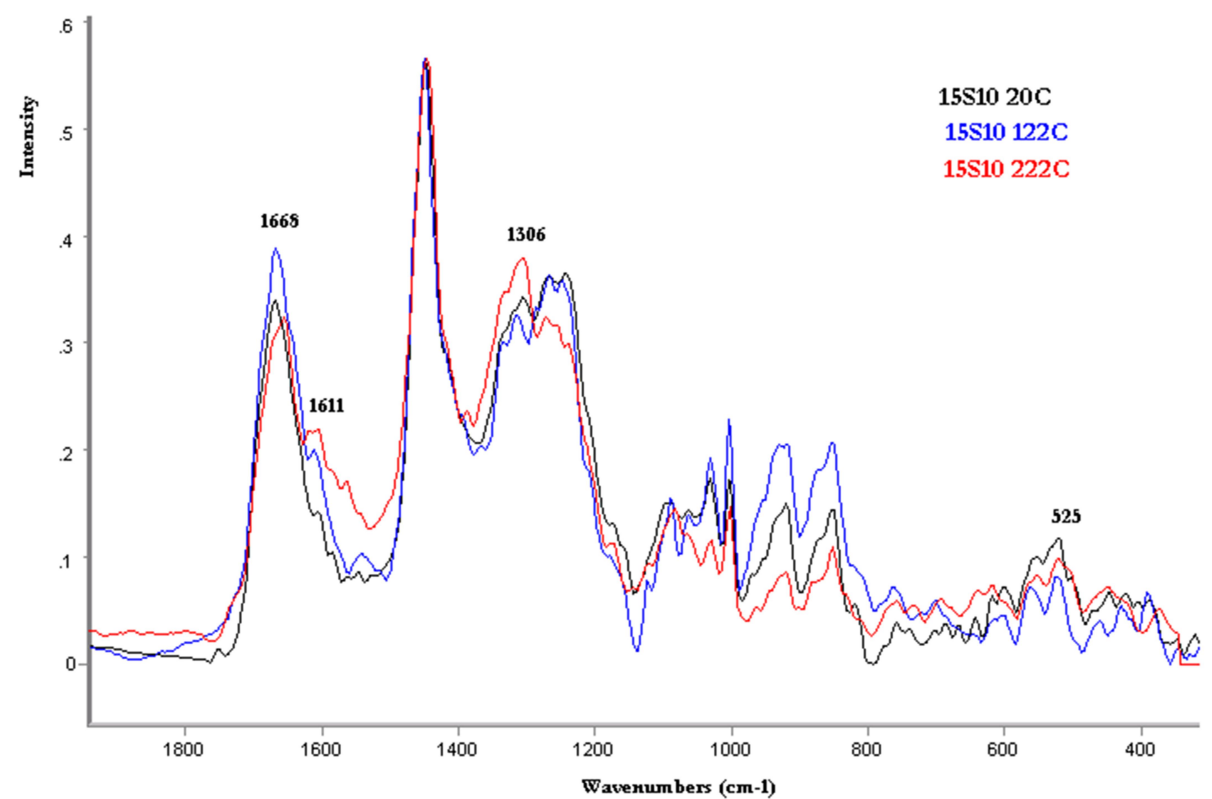

Figure 4 FTR spectra: human burn skin in presence of OSA, heated up in the temperature range: $20-222^{\circ} \mathrm{C}(15 S 1020 \mathrm{C}, 15 S 10122 \mathrm{C}, 15 S 10222 \mathrm{C})\left(3500-400 \mathrm{~cm}^{-1}\right.$ A) (1800-400 $\mathrm{cm}^{-1}$ B).

the tested biological material, ends at a temperature of almost $30^{\circ} \mathrm{C}$ lower than in the case of the 21S skin series (Table 5). The highest thermal stability is observed in the BS SA and BS GO amniotic samples (the enlargement presented in Figure 10 shows the minimum temperature values on the DTG curves indicated in italics). The difference between the BS SA sample and the most outlier in terms of low temperature among the whole series - the $\mathrm{BS}_{4} \mathrm{SiO}_{4}$ sample is more than $35^{\circ} \mathrm{C}$. Unlike in the case of the $21 \mathrm{~S}$ skin series samples, the nature of the transformation corresponding to the essential stage of thermal dissociation corresponding to the degradation of organic material of the samples occurring at the temperature between slightly above $190^{\circ} \mathrm{C}$ and circa $550^{\circ} \mathrm{C}$ is more complex - two- or even three-step (BS, BS SA and BS OSA samples). In the temperature above $550^{\circ} \mathrm{C}$, the nature of the TG curves is analogous to that of the $21 \mathrm{~S}$ skin series, ie the non-modified BS sample does not show a maximum on the DTG curve. Compared to the 21S skin series, the samples of 

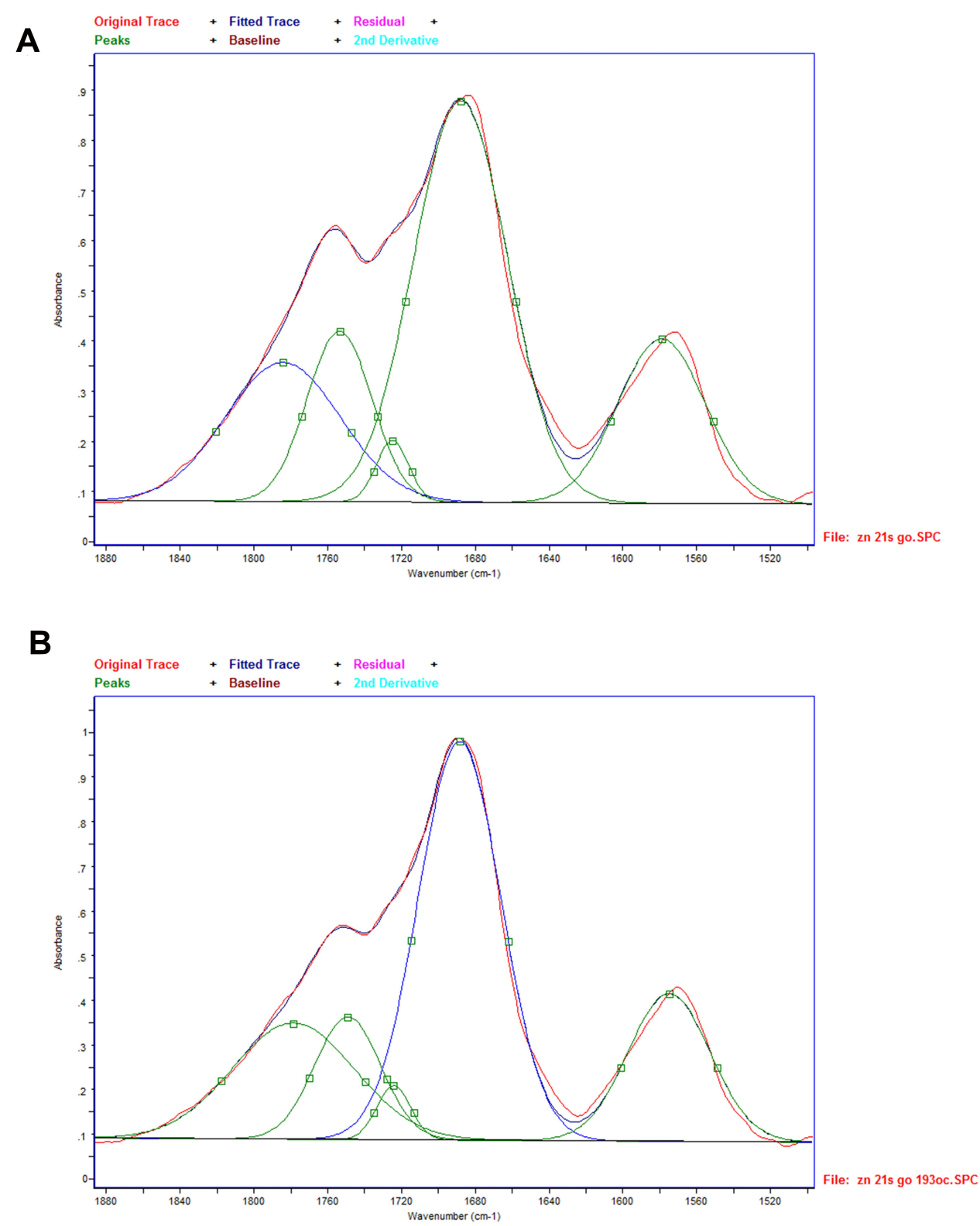

Figure 5 (A and B) Examples of the IR spectrum resolved into Gaussian-shaped bands at around $1750-1500 \mathrm{~cm}^{-1}$ attributed to lipid bands of the samples of human burn skin incubated in the presence of graphene oxide (2IS GO) and heated to $193^{\circ} \mathrm{C}(2 \mathrm{ISGO} 193)$.

the $\mathrm{BS}$ amnion series demonstrate a much higher dispersion of the residual values after heating in the nitrogen up to $800^{\circ} \mathrm{C}$ (as much as $10.3 \%$ ) depending on the modification used.

\section{LOI}

LOI-based flammability tests showed an increase in the oxygen index for the treatment of research material (burn skin and amnion) with silicon-based compounds $\left(\mathrm{H}_{4} \mathrm{SiO}_{4}\right.$ $\times \mathrm{nH}_{2} \mathrm{O}$ and stabilized orthosilicic acid OSA) as well as antioxidants (sodium ascorbate and ascorbic acid) compared to the comparative sample (non-treated) (Table 6).
Improvement of non-inflammatory properties by the treatment of polymeric material with antipyrine in the form of silicon compounds is based on physical processes. In the case of polymer burning, mainly a charred layer strengthened by the presence of silicon compounds is formed on the surface. This layer provides thermal insulation to protect the polymer, moreover, it creates a barrier impeding migration of volatile products of thermal degradation of the material to its surface. ${ }^{23-26}$ In addition, the SEM microphotography analysis confirms the formation of a very clear, flexible coating on the surface of biochar. ${ }^{23}$ 
Table 2 Analysis of Resolved into Gaussian-Shaped Lipid Bands

\begin{tabular}{|l|l|l|l|l|}
\hline Samples & Center $\left(\mathbf{c m}^{-\mathbf{1}}\right)$ & Height & Area & Width \\
\hline 2ISGO & 1784 & 0.28 & 73.60 & 21.68 \\
& 1754 & 0.34 & 41.49 & 14.99 \\
& 1725 & 0.12 & 20.73 & 2.70 \\
& 1688 & 0.80 & 60.16 & 51.27 \\
& 1579 & 0.33 & 55.93 & 19.47 \\
\hline \multirow{2}{*}{ IS GO 193 } & 1779 & 0.26 & 77.97 & 21.50 \\
& 1749 & 0.27 & 42.20 & 12.29 \\
& 1724 & 0.12 & 21.50 & 2.78 \\
& 1688 & 0.89 & 52.86 & 50.24 \\
& 1575 & 0.33 & 52.33 & 18.38 \\
\hline
\end{tabular}

This coating is likely to impede the release of pyrolysis gaseous products into the flame zone, thereby reducing the burning process. The study is of considerable interest, especially with regard to explaining the flame inhibition mechanism.

\section{Microbiological Tests}

The purpose of the comparative microbiological study was to assess anti-inflammatory and antibacterial bioactivity in the tested samples of skin degraded in thermal injury ${ }^{8}$ and hypotrophic amnion (Tables 7 and 8), presented against the analysis of patterns, active antioxidants: AA and SA (Table 9, Figure 11).

In particular, the microbiological activity study for hypotrophic amnion BS samples incubated in the stabilised orthosilicic acid OSA was characterised by good resistance to the bacteria Escherichia coli (growth inhibition zone: $4 \mathrm{~mm}$ ) (Table 7). The study presented in Table 5 shows good resistance to the $S$. aureus bacteria (growth inhibition zone:

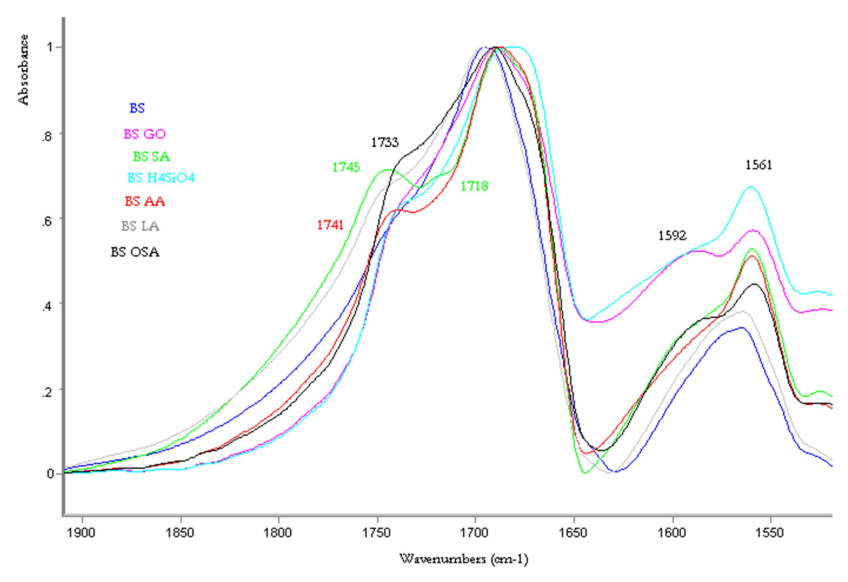

Figure 6 Fragment of FTIR spectra $\left(1900-1550 \mathrm{~cm}^{-1}\right)$ : amniotic samples (BS) in the presence of the following modifiers: OSA, GO, SA, AA, $\mathrm{H}_{4} \mathrm{SiO}_{4}$, lactoferrin.
$3 \mathrm{~mm}$ ) of the IW LF amnion sample. The impact of ascorbic acid AA and sodium ascorbate SA on the hypotrophic amniotic BS and IW samples (Tables 7 and 8, Figure 11) also showed good resistance to the $S$. aureus and $E$. coli bacteria. Whereas for the samples of active antioxidant patterns, the growth inhibition zones compared to the bacteria $S$. aureus, E. coli, P.aeruginosa were between $0.5 \mathrm{~mm}$ and $10 \mathrm{~mm}$ (Table 9, Figure 11). The conducted microbiological study and its results allow us to conclude that pathogenic bacteria commonly causing amniotic infections and growing in burn wounds were found to have good resistance to the applied active antioxidants.

\section{Discussion}

The study of regeneration processes of the damaged tissue on a molecular level should include a search for new active antioxidants. Apart from the ascorbic acid (AA) and sodium ascorbate (SA) discussed in other studies, ${ }^{7,8}$ such substances also include graphene oxide and orthosilicic acid solutions $\left(\mathrm{H}_{4} \mathrm{SiO}_{4} \times \mathrm{nH}_{2} \mathrm{O}\right)$ applied in different concentrations of the modifier to the samples of epidermis degraded in thermal burn. Our own spectroscopic studies and the literature data ${ }^{22,27}$ led us to a general conclusion that the lack of lipid band approx. $1743 \mathrm{~cm}^{-1}$ ie the band associated with ester group vibrations in phospholipids of cell membranes ${ }^{21,22}$ and lack of significant differences in basic collagen I-III amid bands testify to the integrity of undamaged dermis and the presence of the $1743 \mathrm{~cm}^{-1}$ band, as well as that the significant shift of the II and III bands towards lower wavenumbers indicate denaturation of burnt epidermis.

The complex multilayer structure of the amnion favours the processes of exchange of bioactive agents. The studies were selected from among a broader spectrum of research into the cellular structure of the amnion. Observations of individual pathological samples frequently reveal a clearly visible lipid band (results in press) for the BS samples, while no apparent inflection is observed, only one wider band is created, overlapping with the amide band (Figure 6). Subtle differences within the band may indicate loss of integrity of the cell membrane, which is particularly apparent in the case of hypotrophic membrane samples. The most characteristic changes are shown in Figure 7 by mathematical determination of the maximum of bands at about $1740 \mathrm{~cm}^{-1}$.

Systematic analysis, in various own studies, of subsequent FTIR spectra and FTR of the epidermis degraded by burn, found that incubation of samples in modifiers' solutions 


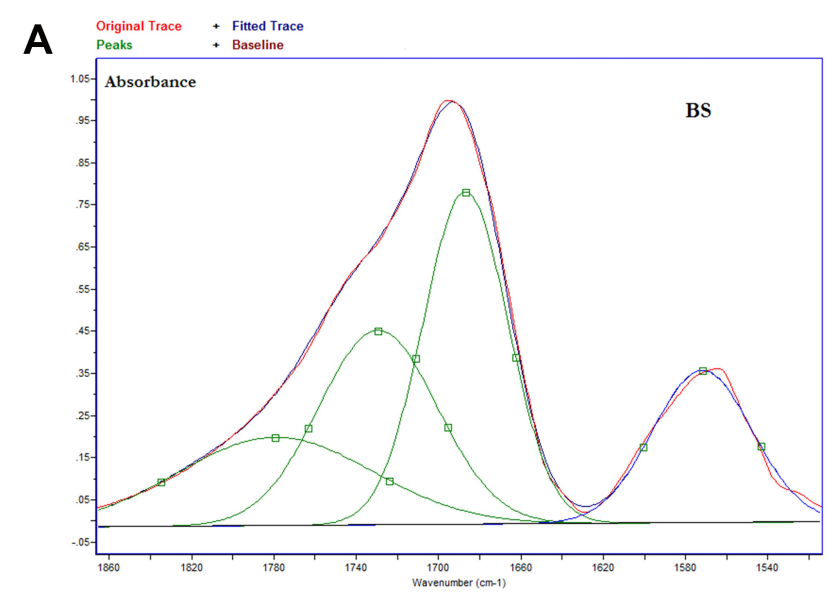

C

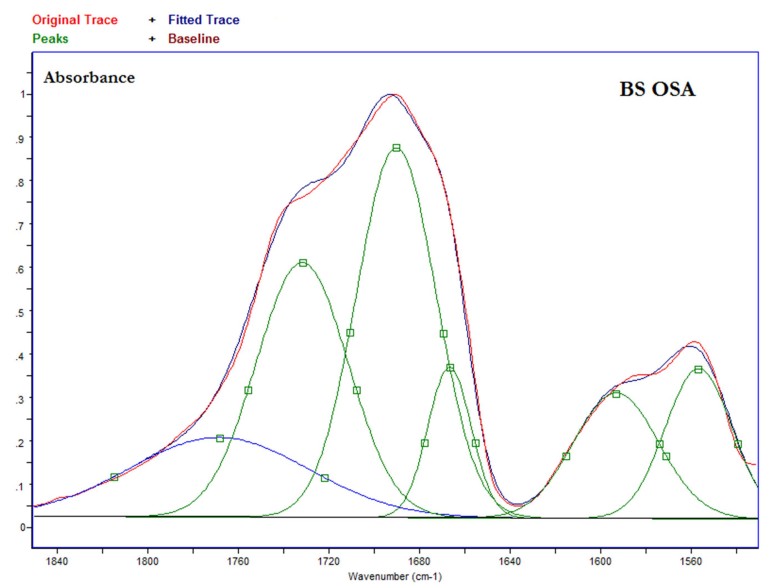

B $\underset{\text { Peaks }}{\text { Original Trace }}+$ Fitted Trace

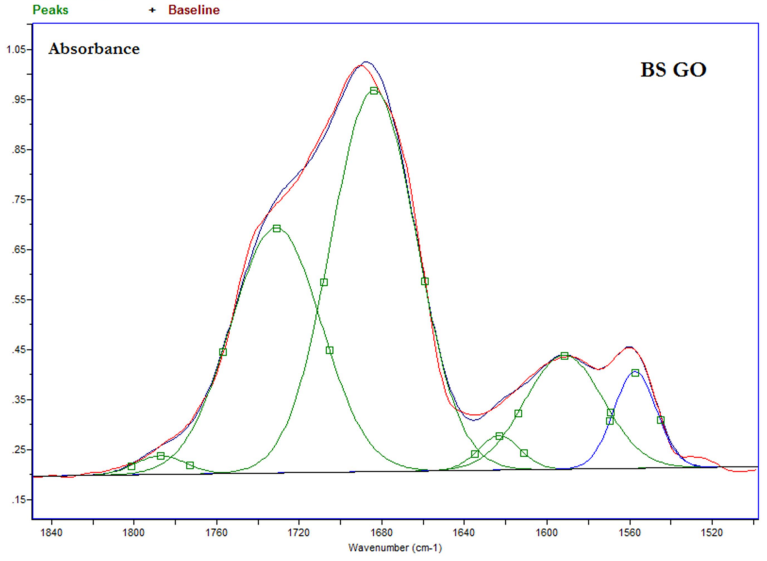

D

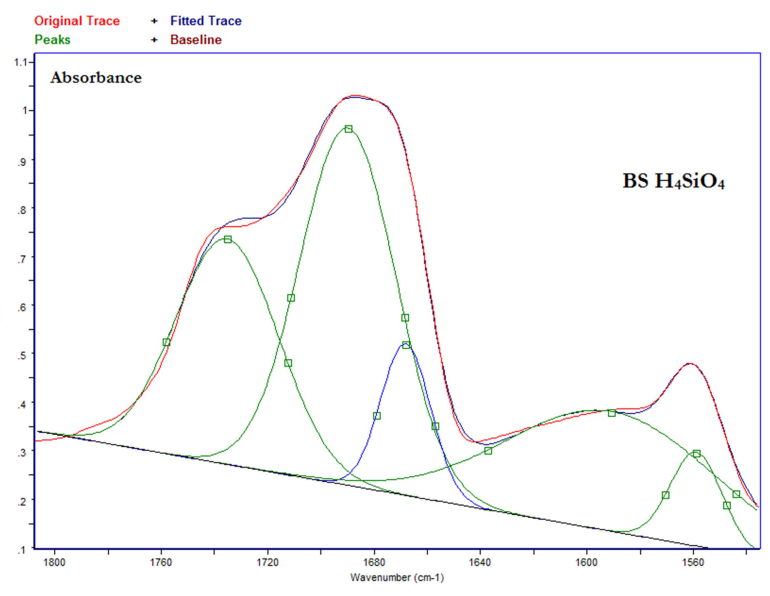

Figure 7 Examples of the IR spectrum resolved into Gaussian-shaped bands at around I750-1500 $\mathrm{cm}^{-1}$ attributed to lipid bands of the samples of amniotic samples (BS) (A) in the presence of the following modifiers: $\mathrm{GO}(\mathbf{B}), \mathrm{OSA}(\mathbf{C}), \mathrm{H}_{4} \mathrm{SiO}$ (D).

results in a shift and changes of the intensity within the broadly understood lipid band, caused predominantly by the presence of the L-ascorbic acid (Figure 3 in the study ${ }^{6}$ ) as the main modifier of the molecular structure of collagen. The analysis of samples of amnion (Figure 6) reveals characteristic changes in the lipid band, as in the case of the L-ascorbic acid AA, which occur during the interaction with sodium ascorbate SA. In this case, next to the intense $1745 \mathrm{~cm}^{-1}$ band, a $1718 \mathrm{~cm}^{-1}$ band is observed (Figure 6). The subject literature[21] ascribed the arm observed for $\sim 1725 \mathrm{~cm}$ to the loss of integrity of cell membrane of the cell subject to necrosis, which makes it more susceptible to oxidative damage. The complex multilayer structure of the amnion favours the processes of exchange of macromolecules and bioactive agents. It seems that in the pathological tissue of hypotrophic amnion integrity of the membrane is broken and its permeability changes. The thesis is confirmed by this interdisciplinary study. For unmodified BS amniotic samples, a lipid band is observed at a wavenumber of $1746 \mathrm{~cm}^{-1}$ (Figure 6); the position of this band and its intensity change during incubation in modifier solutions, whereby the most obvious changes in the lipid band are observed for the following samples: BS OSA and BS $\mathrm{H}_{4}$ $\mathrm{SiO}_{4} 1737 \mathrm{~cm}^{-1}$ and BS GO $1754 \mathrm{~cm}^{-1}$, but also for BS AA samples $1741 \mathrm{~cm}^{-1}$ (Figure 7). LOI-based flammability tests showed an increase in the oxygen index for the treatment of the amnion with antioxidants (BS AA and BS SA) compared to the non-modified comparative BS sample (Table 6). The effect of ascorbic acid AA and sodium ascorbate SA on the samples of hypotrophic amnion BS and IW (Tables 7 and 8) revealed good resistance to the $S$. aureus and $E$. coli bacteria, causing non-specific infection of amniotic cavity, the socalled amniotic infection syndrome. All of the observations enable considering the use of amnion, after it has been modified with antioxidants, for transplantation and organ regeneration. 
Table 3 Analysis of Resolved into Gaussian-Shaped Prominent Bands Occurring in Amniotic Tissue

\begin{tabular}{|l|l|l|l|l|}
\hline Samples & Center $\left(\mathrm{cm}^{-1}\right)$ & Height & Area & Width \\
\hline BS & 1779 & 0.21 & 111.15 & 23.99 \\
& 1729 & 0.46 & 67.75 & 33.26 \\
& 1687 & 0.79 & 48.76 & 40.96 \\
& 1572 & 0.36 & 56.97 & 21.72 \\
\hline${\text { BS } \mathrm{H}_{4} \mathrm{SiO}_{4}}$ & 1735 & 0.46 & 45.55 & 22.50 \\
& 1690 & 0.74 & 42.64 & 33.39 \\
& 1668 & 0.31 & 22.20 & 7.38 \\
& 1591 & 0.25 & 93.18 & 22.55 \\
& 1559 & 0.19 & 22.96 & 4.69 \\
\hline BS OSA & 1768 & 0.18 & 92.88 & 17.79 \\
& 1732 & 0.59 & 47.83 & 29.94 \\
& 1690 & 0.85 & 41.40 & 37.64 \\
& 1667 & 0.35 & 22.62 & 8.35 \\
& 1593 & 0.29 & 44.30 & 13.63 \\
& 1557 & 0.35 & 34.75 & 12.37 \\
\hline BS lactoferrin & 1790 & 0.04 & 28.05 & 1.11 \\
& 1732 & 0.49 & 51.84 & 27.02 \\
& 1687 & 0.76 & 49.04 & 39.80 \\
& 1572 & 0.07 & 23.96 & 1.74 \\
& 1787 & 0.23 & 44.71 & 10.81 \\
& 1731 & 0.19 & 24.34 & 4.99 \\
\hline & 1684 & 0.28 & 123.41 & 34.24 \\
& 1623 & 0.56 & 73.55 & 43.60 \\
& 1592 & 48.36 & 40.15 \\
& 1557 & 67.10 & 30.70 \\
\hline
\end{tabular}

Apart from the AA and SA antioxidants which are mentioned above and discussed in other studies, ${ }^{7,8}$ applied in different concentrations to the samples of epidermis degraded in burn, orthosilicic acid solutions $\left(\mathrm{H}_{4} \mathrm{SiO}_{4} \times \mathrm{nH}_{2}\right.$ O) also cause a number of changes at the molecular level. Studies with the use of IR spectroscopy revealed that incubation of the burnt epidermis in 7\% orthosilicic acid causes a shift of amide II band towards the lower wavenumbers characteristic for allogeneic, undamaged skin $\left(1548 \mathrm{~cm}^{-1}\right)$ for SP Table 1 in the study. ${ }^{8}$ Scanning microscopy images on the surface of the epidermis reveal a protective membrane of a composite character (Figure 2B) in the study. ${ }^{7}$ Whereas LOI-based flammability tests showed an increase in the oxygen index for the treatment of research material (burn skin and amnion) with silicon-based compounds $\left(\mathrm{H}_{4}\right.$ $\mathrm{SiO}_{4} \times \mathrm{nH}_{2} \mathrm{O}$ and stabilized orthosilicic acid) as well as antioxidants (sodium ascorbate and ascorbic acid) compared to the non-treated sample (Table 6). Similarly, microbiological studies ${ }^{8}$ aimed at anticipating anti-inflammatory and antibacterial bioactivity for skin samples incubated in the $7 \%$ orthosilicic acid were characterised by good resistance to the following bacteria: Staphylococcus aureus and Escherichia coli. It is worth mentioning that Staphylococcus aureus is one of the most important bacterial pathogens in humans, which causes colonization of skin and mucous membranes. Staphylococcus aureus may be the cause of the so-called Staphylococcal Scalded Skin Syndrome (SSSS). The illness is caused by epidermolysin, ie a toxin produced by Staphylococcus aureus, spread to blood from the primary source of infection.

The question of whether the stabilized ortho-silicic acid (OSA) diluted to nanoconcentration modifies the necrotic scab degraded during thermal burn is a complex one. Modification of the samples and their incubation in OSA of a concentration of 1:6000 results in amide I bands shift to the frequency characteristic of the native form of collagen in allogeneic undamaged human skin samples ( $\alpha$-helix: $1659 \mathrm{~cm}^{-1}$ for SP (Table 1), from the study. ${ }^{8}$ However, a more detailed analysis suggests that the following factors can be involved: structural tissue variability, concentration of the applied modifier and the OSA acid, individual susceptibility to thermal degradation and others. In this study, the character of changes occurring up to $220^{\circ} \mathrm{C}$ which are observed in the thermogravimetric studies, for skin samples of the $21 \mathrm{~S}$ and $15 \mathrm{~S}$ series, is different (Figure 9A). The DTG curves for the $21 \mathrm{~S}$ series present only one maximum. Studies with the use of the IR spectroscopy method reveal that the profile of the spectrum in the I-III band, as well as in the whole lipid area, is different for both trials (21S and $15 \mathrm{~S}$ ), which testifies to variability of the tissue (Figure 9B). This variability is observed both when comparing the $15 \mathrm{~S}$ and 21S samples (Figure 1), and when selecting concentrations of modifiers for the tested samples (Figure 8A and B). For the $21 \mathrm{~S}$ sample, once its components are broken down, the following lipid bands are observed: 1792, 1757, $1735 \mathrm{~cm}^{-1}$ (Figure 2), for sample $15 \mathrm{~S}$ a single $1743 \mathrm{~cm}^{-1}$ band becomes apparent (Figure 1). This band is highly susceptible to membrane modifications during incubation in OSA: $1751 \mathrm{~cm}^{-1}$ for sample 15S2, 1747 and $1729 \mathrm{~cm}^{-1}$ for sample $15 \mathrm{~S} 6,1720 \mathrm{~cm}^{-1}$, up to the flattening of the $15 \mathrm{~S} 10$ sample. Therefore, the sample of 1:10,000 OSA concentration (15S10) was the subject of a detailed thermogravimetric analysis in this study. In the case of the $15 \mathrm{~S} 10$ sample heated successively at temperatures of $122-256^{\circ} \mathrm{C}$, a wide range of the lipid band is observed (Figure 3). Whereas heating the sample to the temperature of $222^{\circ} \mathrm{C}$ and $256^{\circ} \mathrm{C}$ activates interactions within the amide III area (IR spectrum, Figure 3) or amide II-III (FTR spectrum, Figure 4), as well as the area characteristic of reactions of stretching 

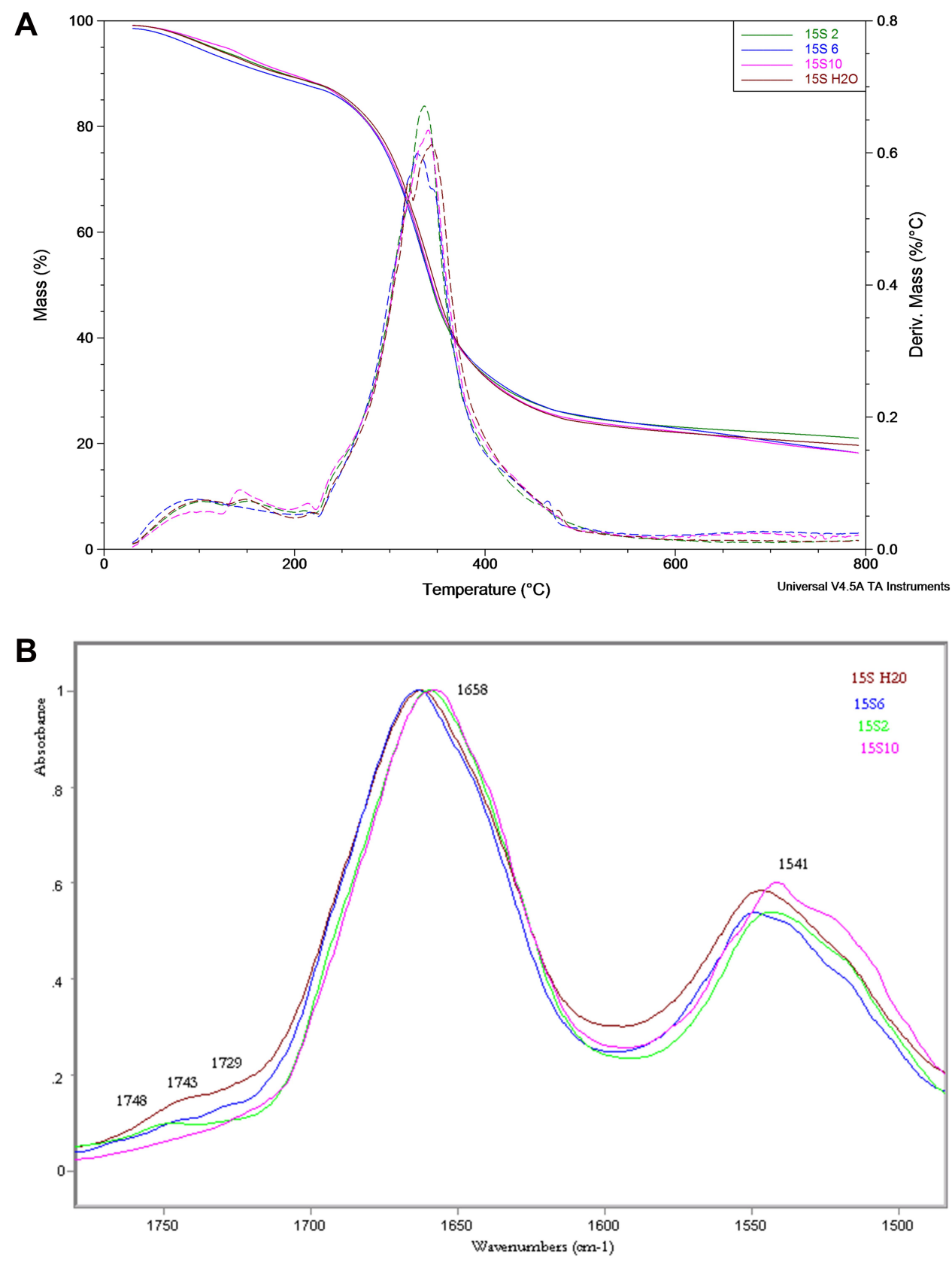

Figure 8 (A) TG and DTG curves for samples of series $15 \mathrm{~S}$ registered in the temperature range of $30-800^{\circ} \mathrm{C}$ in nitrogen, purge $60 \mathrm{~mL} / \mathrm{min}$. Heating rate $20 \% \mathrm{~min}$. (B) Fragment of FTIR spectra $\left(1700-1400 \mathrm{~cm}^{-1}\right)$ : human burn skin in presence of silicic acid OSA (I5S6; I5SI0; I5S2).

vibration band at $1085 \mathrm{~cm}^{-1}$ discussed earlier in the study. ${ }^{8}$ It is worth emphasising that the amide II-III area is particularly active in oxidation-reduction activities, and such changes are always observed in the burn process. Interestingly, in the same amide II-III area, changes were found after modification of amniotic samples in $\mathrm{GO}$, OSA and $\mathrm{H}_{4} \mathrm{SiO}_{4}$. However, the changes for amniotic samples are even more significant as they are visible during incubation at room temperature. In this case, the amide II band is split into two components (1592 and $1557 \mathrm{~cm}^{-1}$ for GO; 1593 and $1557 \mathrm{~cm}^{-1}$ for OSA;
1591 and $1559 \mathrm{~cm}^{-1}$ for $\mathrm{H}_{4} \mathrm{SiO}_{4}$ ) (Figure 7). Thus, the amide II area is activated during the incubation of amnion in the modifiers, ie an area particularly active when the tissue is affected by oxidative stress. ${ }^{6}$ The changes described above and results analysed in detail in this study allow us to conclude that the whole $1760-1500 \mathrm{~cm}^{-1}$ area will be responsible for membrane modifications concerning the intramolecular impact of stabilized ortho-silicic acid OSA nanoconcentrations. Similarly, the microbiological activity study ${ }^{8}$ for skin and amnion samples incubated in the ortho-silicic acid OSA were characterised by 

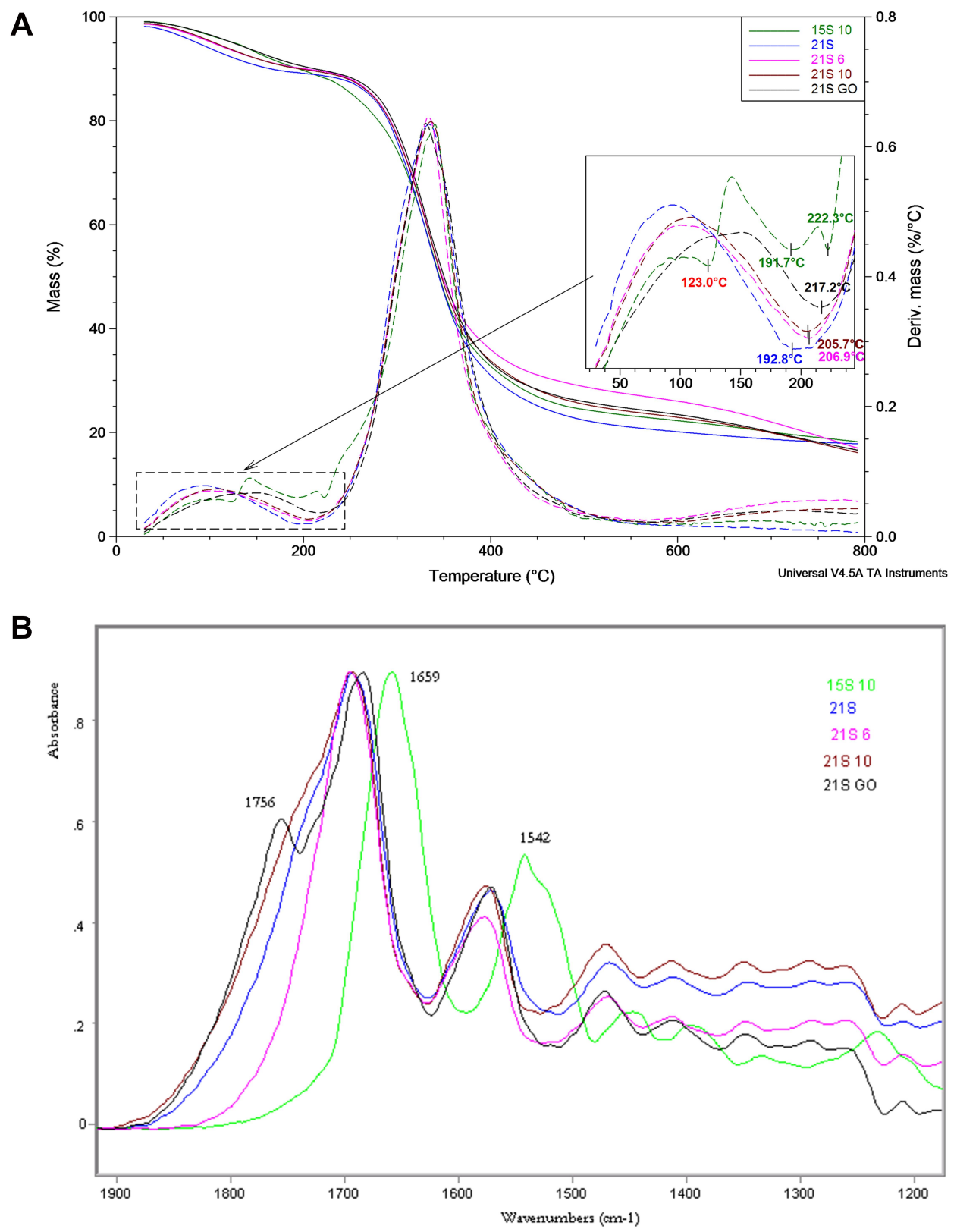

Figure 9 (A) TG (solid) and DTG (dashed) curves registered for samples of skins from the 2 IS series and comparatively skin I5SI0 during heating in nitrogen from ambient temperature to $800^{\circ} \mathrm{C}$ at a rate of $20^{\circ} / \mathrm{min}$. (B) FTIR spectra: human burn skin in presence of silicic acid OSA (I5SI0, 2ISI0, 2IS6) and human burn skin in the presence of graphene oxide (2IS GO).

good resistance to the following bacteria: Staphylococcus aureus and Escherichia coli (growth inhibition zone: $4 \mathrm{~mm}$ ) of the BS OSA amnion sample (Table 7). Similarly, LOI-based flammability tests showed an increase in the oxygen index for the treatment of research material (burn skin and amnion) with stabilized ortho-silicic acid OSA compared to the comparative sample (Table 6).

Thus, modification of samples with silicon-based compounds may be used for transplantation and organ regeneration. The preliminary results concerning treatment of the samples with graphene oxide are promising. Within the stream of comparative research, it should be noted, on the basis of thermogravimetric studies, that the epidermis degraded as a result of burn (sample 21S GO) modified with graphene oxide is characterised by the greatest stability. The beginning of the essential stage of thermal dissociation (degradation) of the organic material corresponding to a minimum on the DTG curve is shifted for the $21 \mathrm{~S} \mathrm{GO}$ sample by $24.4^{\circ} \mathrm{C}$ compared to the non-modified $21 \mathrm{~S}$ sample (Figure 9). In the case of the 21S GO samples analysed in the infrared studies, a relatively intense lipid band appears. This band is shifted to lower wavenumbers of 
Table 4 Values of Mass Loss in Subsequent Thermal Transitions of the Skin I5SIO and Samples of Skins from the Series $21 S$

\begin{tabular}{|c|c|c|c|c|}
\hline \multirow[t]{2}{*}{ Sample } & $\begin{array}{l}\text { Loss of } \\
\text { Mass } \\
\text { Up to } \\
220^{\circ} \mathrm{C}\end{array}$ & $\begin{array}{l}\text { Loss of Mass in } \\
\text { the Range of } \\
220-550^{\circ} \mathrm{C}\end{array}$ & $\begin{array}{c}\text { Loss of Mass } \\
\text { in the Range } \\
\text { of } 550-800^{\circ} \\
\text { C }\end{array}$ & $\begin{array}{c}\text { Residue at } \\
8000^{\circ} \mathrm{C}\end{array}$ \\
\hline & $\Delta m_{1}, \%$ & $\Delta m_{2}, \%$ & $\Delta m_{3}, \%$ & $R, \%$ \\
\hline $15 S 10$ & 10.7 & 65.1 & 8.0 & 18.2 \\
\hline $2 I S$ & 9.4 & 67.7 & 3.2 & 17.8 \\
\hline 2156 & 9.1 & 62.2 & 10.3 & 17.0 \\
\hline 21510 & 9.4 & 65.3 & 7.9 & 16.1 \\
\hline $21 S$ GO & 9.3 & 65.1 & 8.0 & 16.6 \\
\hline
\end{tabular}

$1749 \mathrm{~cm}^{-1}$ for the sample $21 \mathrm{~S}$ GO193 heated to the temperature of $193^{\circ} \mathrm{C}$ (Figure 1). Whereas in the case of the modified amnion samples, the thermogravimetric studies revealed the highest stability of the BS GO and BS SA samples (Figure 10). Therefore, the burn degraded epidermis and pathological amnion continue to demonstrate susceptibility to membrane lipid interactions. Significant shifts (Figures 1 and 5) within the range of amide I-II bands (21S $1693,1580 \mathrm{~cm}^{-1}$ 21SGO $16881579 \mathrm{~cm}^{-1} 21 \mathrm{~S} \mathrm{GO1931688}$ $1575 \mathrm{~cm}^{-1}$ ) are also observed. In particular, the effect of graphene oxide on the $21 \mathrm{~S}$ GO193 sample heated to $193^{\circ} \mathrm{C}$ is likely to convert to a-helix $\leftrightarrow \beta$-sheet $\leftrightarrow$ tums $\leftrightarrow$ disordered. ${ }^{25,26,28,29}$ On the other hand, the amide II-III area is particularly active in the oxidation-reduction interactions observed in the burn process. It was also noticed that
Table 5 Values of Mass Loss in Subsequent Thermal Transitions of Amniotic Samples of the BS Series

\begin{tabular}{|l|c|c|c|c|}
\hline Sample & $\begin{array}{c}\text { Loss of } \\
\text { Mass } \\
\text { Up to } \\
190^{\circ} \mathbf{C}\end{array}$ & $\begin{array}{c}\text { Loss of Mass in } \\
\text { the Range of } \\
190-550^{\circ} \mathbf{C}\end{array}$ & $\begin{array}{c}\text { Loss of Mass } \\
\text { in the range } \\
\text { of 550-800 }{ }^{\circ} \mathbf{C}\end{array}$ & $\begin{array}{c}\text { Residue at } \\
800{ }^{\circ} \mathbf{C}\end{array}$ \\
\cline { 2 - 5 } & $\Delta m_{1}, \%$ & $\Delta m_{2}, \%$ & $\Delta m_{3}, \%$ & $R, \%$ \\
\hline BS & 9.7 & 68.7 & 3.7 & 16.8 \\
BS AA & 8.1 & 63.8 & 7.3 & 18.8 \\
BS OSA & 9.0 & 66.7 & 6.8 & 16.1 \\
BS SA & 9.1 & 68.2 & 9.7 & 11.4 \\
BS GO & 8.8 & 67.3 & 11.0 & 16.1 \\
BS H ${ }_{4} S i O_{4}$ & 9.6 & 65.0 & 11.6 & 16.1 \\
$B S ~ L F$ & 7.9 & 64.1 & 5.8 & 21.4 \\
\hline
\end{tabular}

after modification of the BS amniotic samples in $\mathrm{GO}$ and OSA and $\mathrm{H}_{4} \mathrm{SiO}_{4}$, the amide II band is split into two components (1592 and $1557 \mathrm{~cm}^{-1}$ for GO; 1593 and $1557 \mathrm{~cm}^{-1}$ for OSA; 1591 and $1559 \mathrm{~cm}^{-1}$ for $\mathrm{H}_{4} \mathrm{SiO}_{4}$ ) (Figure 7). This clearly attests to the susceptibility to membrane modifications, at molecular and supramolecular levels, of the threelayer structure of the amnion, which includes fibrous and non-fibrous collagens type I, II, III and V, glycoproteins, proteoglycans and, especially rich in the chain, heparan sulphate. It is worth noting that incubation of the BS amniotic samples in all modifiers in question (except for lactoferrin) causes shifts: of amide I-II bands to lower wavenumber values and amide III to higher wavenumber values (Figure

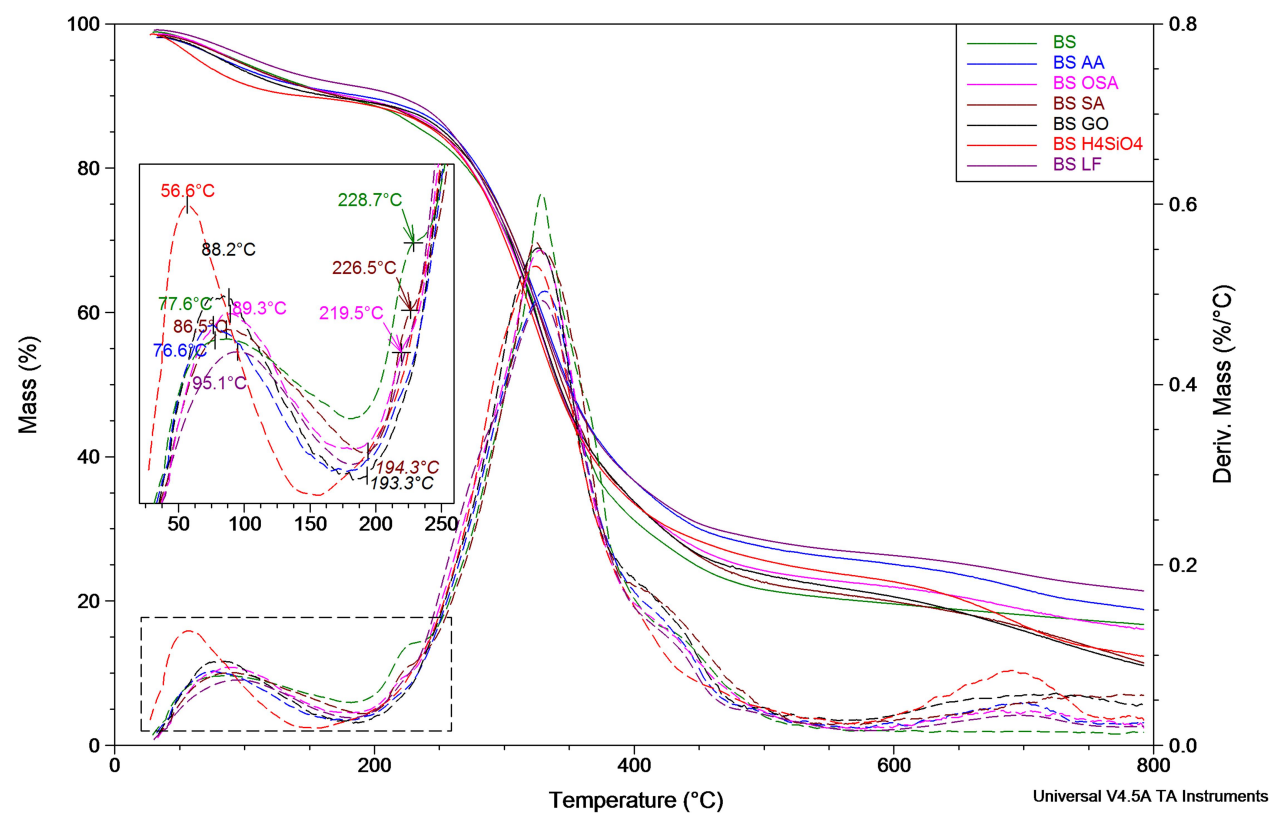

Figure 10 TG (solid) and DTG (dashed) curves registered for amniotic samples of series BS during heating in nitrogen from ambient temperature to $800^{\circ} \mathrm{C}$ at a rate of $20 \%$ min. 
Table 6 Results of Limiting Oxygen Index LOI

\begin{tabular}{|c|c|}
\hline \multicolumn{2}{|c|}{ Human Burn Injury Skin Samples } \\
\hline & LOI \% \\
\hline \multicolumn{2}{|l|}{ Human burn skin in presence of $\mathrm{H}_{4} \mathrm{SiO}_{4}$} \\
\hline SB & 24.6 \\
\hline $\mathrm{SB}\left(3 \% \mathrm{H}_{4} \mathrm{SiO}_{4} \times \mathrm{nH}_{2} \mathrm{O}\right)$ & 25.8 \\
\hline $\mathrm{SB}\left(0.96 \% \mathrm{H}_{4} \mathrm{SiO}_{4} \times \mathrm{nH}_{2} \mathrm{O}\right)$ & 25.6 \\
\hline SB $\left(0.096 \% \mathrm{H}_{4} \mathrm{SiO}_{4} \times \mathrm{nH}_{2} \mathrm{O}\right)$ & 25.3 \\
\hline $\mathrm{SB}\left(0.0096 \% \mathrm{H}_{4} \mathrm{SiO}_{4} \times \mathrm{nH}_{2} \mathrm{O}\right)$ & 25 \\
\hline $\mathrm{SB}\left(0.00096 \% \mathrm{H}_{4} \mathrm{SiO}_{4} \times \mathrm{nH}_{2} \mathrm{O}\right)$ & 25 \\
\hline \multicolumn{2}{|l|}{ Human burn skin in presence of OSA } \\
\hline SB $(1: 10,000$ OSA $)$ & 24 \\
\hline SB $(1: 8000$ OSA $)$ & 24.2 \\
\hline SB (1:6000; I:4000; I:2000 OSA) & 24.4 \\
\hline \multicolumn{2}{|c|}{$\begin{array}{c}\text { Amniotic Samples BS in Presence of OSA, GO, SA, AA, } \\
\text { H4SiO4, LF }\end{array}$} \\
\hline & LOI \% \\
\hline BS & 20.4 \\
\hline BS $(0.00 \mathrm{lg}$ GO) & 22.3 \\
\hline $\mathrm{BS}(0.00 \mathrm{lg}$ OSA $)$ & 22 \\
\hline BS $(0.00 \lg$ SA $)$ & 22.5 \\
\hline $\mathrm{BS}(0.00 \mathrm{lg} \mathrm{AA})$ & 22.5 \\
\hline $\mathrm{BS}(0.00 \mathrm{lg}$ LF $)$ & 21.5 \\
\hline $\mathrm{BS} 0.00 \mathrm{Ig}\left(\mathrm{H}_{4} \mathrm{SiO}_{4} \times \mathrm{nH}_{2} \mathrm{O}\right)$ & 21.8 \\
\hline
\end{tabular}

6). Although the spectral changes observed for lactoferrin (Figures 6 and 7), thermogravimetric (Figure 10) and the low-flammability characteristics (Table 3) are not as spectacular as in the case of other modifiers, the biochemical impact of this protein on the amniotic membrane is worth analysing. Importantly, pathogenic bacteria which

Table 7 Amniotic Samples BS Incubated in 0.00 I g: OSA, GO, SA, AA, $\mathrm{H}_{4} \mathrm{SiO}_{4}$, LF - Resistance of Escherichia coli and Staphylococcus aureus

\begin{tabular}{|l|c|c|}
\hline \multirow{2}{*}{ Samples } & \multicolumn{2}{|c|}{ The Inhibition Growth Zone [mm] } \\
\cline { 2 - 3 } & S. aureus & E. coli \\
\hline BS & $\mathrm{I}$ & $\mathrm{I}$ \\
$\mathrm{BS} \mathrm{GO}$ & $\mathrm{I}$ & 0,5 \\
$\mathrm{BS} \mathrm{LF}$ & 0,5 & $\mathrm{I}$ \\
$\mathrm{BS} \mathrm{SA}$ & 0,5 & $\mathrm{I}$ \\
$\mathrm{BS} \mathrm{H}_{4} \mathrm{SiO}_{4}$ & $\mathrm{I}$ & 0,5 \\
BS AA & $\mathrm{I}$ & $\mathrm{I}$ \\
BS OSA & 0,5 & 4 \\
\hline
\end{tabular}

Note: The samples of hypotrophic amnion BS were incubated in solutions containing $0.00 \mathrm{Ig}$ of the following antioxidants: OSA, GO, SA, AA, $\mathrm{H}_{4} \mathrm{SiO}_{4}$, LF.
Table 8 Amniotic Samples IW Incubated in 0.00Ig: OSA, GO, $\mathrm{SA}, \mathrm{AA}, \mathrm{H}_{4} \mathrm{SiO}_{4}$, LF - Resistance of Escherichia coli, Staphylococcus aureus and $\mathrm{E}$. faecalis

\begin{tabular}{|l|c|c|c|}
\hline \multirow{2}{*}{ Samples } & \multicolumn{3}{|c|}{ The Inhibition Growth Zone [mm] } \\
& S. aureus & E. coli & E. faecalis \\
\hline IW & 2 & 0,5 & 0,5 \\
IW GO & $\mathrm{I}$ & 0,5 & 0,5 \\
IW OSA & 0,5 & 0,5 & 0,5 \\
IW SA & 2 & 0,5 & 0,5 \\
IW AA & 1 & 0,5 & 0,5 \\
IW LF & 3 & 0,5 & 0,5 \\
IW $\mathrm{H}_{4} \mathrm{SiO}_{4}$ & 0,5 & 0,5 & 0,5 \\
\hline
\end{tabular}

Note: The samples of hypotrophic amnion IW were incubated in amniotic fluid containing $0.00 \mathrm{lg}$ of the following antioxidants: OSA, GO, SA, AA, $\mathrm{H}_{4} \mathrm{SiO}_{4}$, $\mathrm{LF}$ in a I:I ratio.

Table 9 Testing of Antioxidant Patterns Performed on Tissue Paper

\begin{tabular}{|l|c|c|c|}
\hline Samples & \multicolumn{3}{|c|}{ The Inhibition Growth Zone [mm] } \\
& S. aureus & E. coli & P. aeruginosa \\
\hline $5 \%$ AA & 10 & 6 & 8 \\
$5 \%$ SA & 2 & 2 & 0,5 \\
\hline
\end{tabular}

commonly caused infections of the amnion were characterised by good resistance to lactoferrin used as a modifier. Research into the anti-inflammatory and antibacterial bioactivity presented in Table 5 revealed good resistance to the $S$. Aureus bacteria (growth inhibition zone: $3 \mathrm{~mm}$ ) of the amnion of the IW LF sample. Lactoferrin (LF) is a glycoprotein commonly found in the body. It is produced by epithelial cells and hence its presence in the secretions on the surface of mucous membranes. ${ }^{30}$ It is also produced by epithelial cells which perform the secretory function and are therefore released to body fluids: milk, saliva, tears, sweat, secretions of the respiratory system, digestive systems and urogenital system. The greatest amount of LF is found in colostrum and mother's milk $(2-15 \mathrm{mg} / \mathrm{mL})$ as well as in tears $(2 \mathrm{mg} / \mathrm{mL})$. The main characteristics stemming from the presence of lactoferrin in the body are determined by its ability to bind iron in the form of chelates and to regulate their release from the digestive tract. It is worth noting that in the fight with iron-dependent peroxidation of lipids, the most effective antioxidants are transferrin ${ }^{31,32}$ ceruloplasmin and lactoferrin. Notably, important biochemical processes which are enhanced by the presence of lactoferrin in the body include oxidation and reduction control, including 


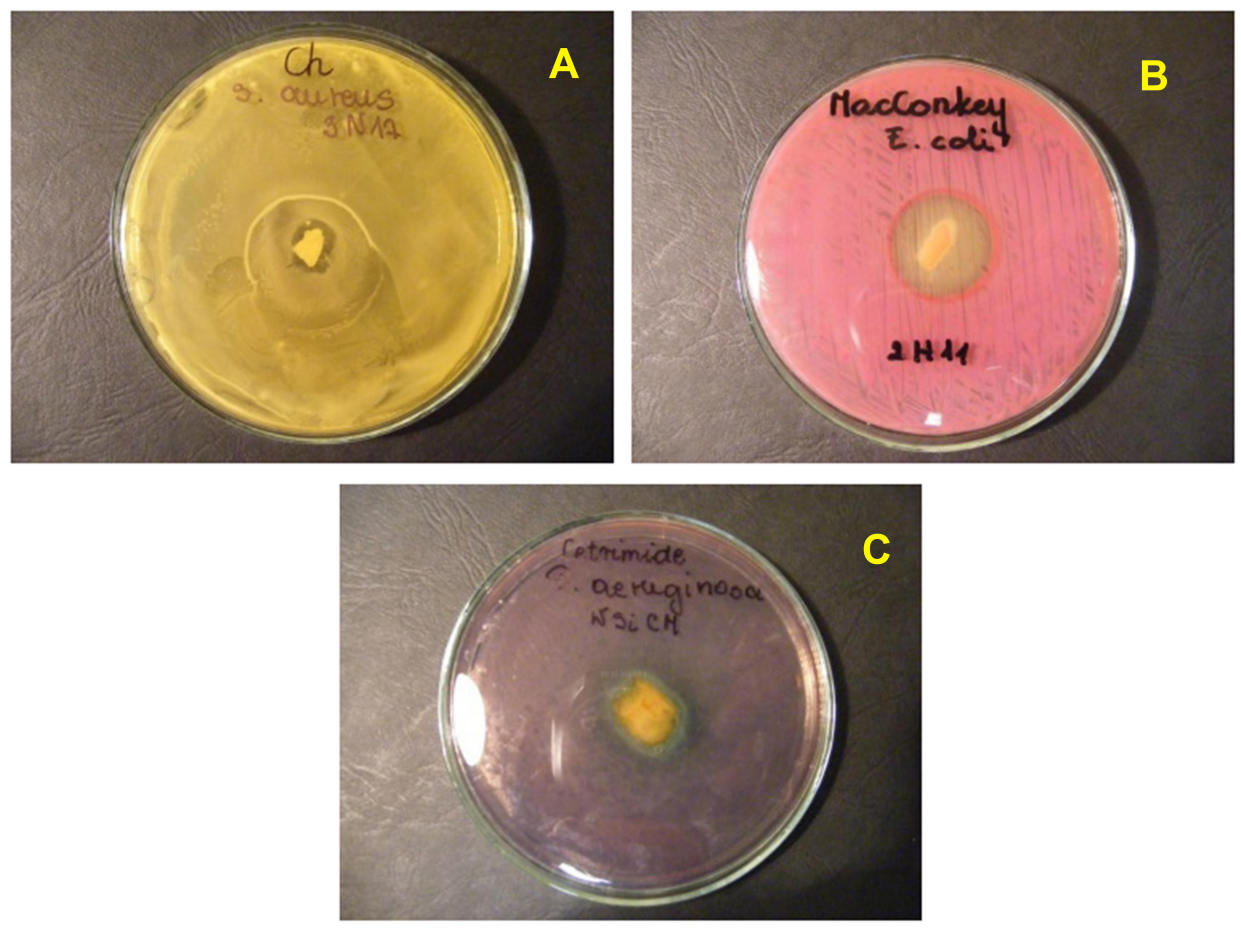

Figure II Photographs of the growth typical inhibition zones for the following bacteria: Staphylococcus aureus (A), Escherichia coli (B), Pseudomonas aeruginosa (C).

the so-called oxidative stress, regulation of free oxygen radicals, neutralising various compounds, including xenobiotics (eg poisons and drugs) as well as inhibiting the growth of microorganisms.

\section{Conclusions}

The optimal concentration and composition of modifiers solutions should become the subject of future analytical studies. This thermogravimetric study found the highest stability of the analysed tissues (hypotrophic amnion and burnt epidermis) after modification with graphene oxide and sodium ascorbate. Studies aiming at producing wound dressings which favour the formation of scarring and inhibit colonisation of wounds by multidrug strains should be interdisciplinary at the molecular (FTIR and Raman spectroscopy) and supramolecular levels (eg SAXS, DTG).

In the present study, it was found that the active antioxidants selected for analysis modify the collagen structure of the amniotic pathological tissue and the epidermis degraded in thermal burns at the molecular (FTIR, FTR), supermolecular (TG) and morphological (LOI, microbiology) levels. Notably, thermogravimetric studies showed the highest stability of the analyzed tissues after modification with graphene oxide and sodium ascorbate. FTIR and FTR spectroscopy methods identified the presence of changes in intensity, particularly important from the point of view of tissue regeneration, within the broadly understood 1743-1745$1747 \mathrm{~cm}^{-1}$ lipid band. In general, it should be stated that research aimed at developing biological dressings that promote scarring and inhibit wound colonization by multi-drug strains should always be carried out as interdisciplinary (eg FTIR, FTR, TG, SAXS, LOI, microbiology).

\section{Disclosure}

Dr Henk-Maarten Laane is an employee of ReXil Agro BVand reports a patent on the stabilisation of silicic acid. The authors report no other potential conflicts of interest for this work.

\section{References}

1. Jaswal S, Mehta HC, Sood AK, Kaur J. Antioxidant status in rheumatoid arthritis and role of antioxidant therapy. Clin Chim Acta. 2003;338 (1-2):123-129. doi:10.1016/j.cccn.2003.08.011

2. Corti A, Casini AF, Pompella A. Cellular pathways for transport and efflux of ascorbate and dehydroascorbate. Arch Biochem Biophys. 2010;2(2):107-115. doi:10.1016/j.abb.2010.05.014

3. Catalan-Latorre A, Ravaghi M, Manca ML, et al. Freeze-dried eudragit-hyaluronan multicompartment liposomes to improve the intestinal bioavailability of curcumin. Eur J Pharm Biopharm. 2016;107:49-55. doi:10.1016/j.ejpb.2016.06.016 
4. Manca ML, Zaru M, Bacchetta G, et al. A new technological approach to improve the efficacy of a traditional herbal medicinal product in wound healing. Ind Crops Prod. 2015;63:71-78. doi:10.1016/j.indcrop.2014.10.049

5. Bobiński R, Mikulska M. The ins and outs of maternal-fetal fatty acid metabolism. Acta Biochim Pol. 2015;62(3):499-507. doi:10.18388/ abp.2015_1067

6. Pielesz A, Ślusarczyk C, Biniaś D, Bobiński R. Sodium ascorbate (SA) and L-ascorbic acid (AA) as modifiers of burn affected skin a comparative analysis. Spectrochim Acta A Mol Biomol Spectrosc. 2019;209:55-61. doi:10.1016/j.saa.2018.10.021

7. Pielesz A, Biniaś D, Sarna E, et al. Active antioxidants in ex-vivo examination of burn wound healing by means of IR and Raman spectroscopies-Preliminary comparative research. Spectrochim Acta A Mol Biomol Spectrosc. 2017;173:924-930. doi:10.1016/j. saa.2016.10.046

8. Pielesz A, Biniaś D, Machnicka A, et al. Stabilized ortho-silicic acid as a modifier of tissue - preliminary comparative biomaterial studies. J Biomed Nanotechnol. 2020;16(4):1-10. doi:10.1166/jbn.2020.2912

9. Pielesz A, Machnicka A, Gawłowski A, Fabia J, Sarna E, Biniaś W. Inhibitors of thermally induced burn incidents - characterization by microbiological procedure, electrophoresis, SEM, DSC and IR spectroscopy. Analyst. 2015;140(13):4599-4607. doi:10.1039/ C5AN00329F

10. Pielesz A, Machnicka A, Sarna E. Modified orthosilicic acid as an inhibitor of thermally induced burn incidents - characterization by microbiological procedure, electrophoresis and SEM. Leczenie Ran. 2015;12(2):73-81. doi:10.15374/LR2015009

11. Pielesz A, Gawłowski A, Fabia J, Ślusarczyk C, Sarna E. Inhibitors of thermally induced burn incidents - the examinations of the flammability, TGA, SAXS and SEM methods. Polimery. 2017;62(11/ 12):1-12. doi:10.14314/polimery.2017.806

12. Hussein KH, Abdelhamid HN, Zou X, Woo HM. Ultrasonicated graphene oxide enhances bone and skin wound regeneration. Mater Sci Eng C. 2019;94:484-492. doi:10.1016/j.msec.2018.09.051

13. Ghaffari A, Moghimi HR, Manafi A, Hosseini H. A mechanistic study on the effect of ethanol and importance of water on permeation of drugs through human third-degree burn eschar. Int Wound J. 2012;9(2):221-229. doi:10.1111/j.1742-481X.2011.00879.x

14. Shah DK, Khandavilli S, Panchagnula R. Alteration of skin hydration and its barrier function by vehicle and permeation enhancers: a study using TGA, FTIR, TEWL and drug permeation as markers. Methods Find Exp Clin Pharmacol. 2008;30(7):499-512. doi:10.1358/ mf.2008.30.7.1159653

15. Zhang W, Zhang QH, Chen GQ, Xing TL. Flame retardancy finishing on wool fabric via sol-gel method. Adv Mater Res. 2014;989:607-610. doi:10.4028/www.scientific.net/AMR.989994.607

16. Abdelhamid HN, Wu HF. Multifunctional graphene magnetic nanosheet decorated with chitosan for highly sensitive detection of pathogenic bacteria. J Mater Chem B. 2013;1(32):3950-3961. doi: $10.1039 / \mathrm{c} 3$ tb20413h

17. Khan MS, Abdelhamid HN, Wu HF. Near infrared (NIR) laser mediated surface activation of graphene oxide nanoflakes for efficient antibacterial, antifungal and wound healing treatment. Colloids Surf $B$ Biointerfaces. 2015;127:281-291. doi:10.1016/j.colsurfb.2014. 12.049
18. Driscoll JA, Brody SL, Kollef MH. The epidemiology, pathogenesis and treatment of pseudomonas aeruginosa infections. Drugs. 2007;67 (3):351-368. doi:10.2165/00003495-200767030-00003

19. Mariencheck WI, Alcorn JF, Palmer SM, Wright JR. Pseudomonas aeruginosa elastase degrades surfactant proteins A and D. Am $J$ Respir Cell Mol Biol. 2003;28(4):528-537. doi:10.1165/ rcmb.2002-01410C

20. Gordon S, Swenson JM, Hill BC, et al. Antimicrobial susceptibility patterns of common and unusual species of enterococci causing infections in the United States. J Clin Microbiol. 1992;30 (9):2373-2378. doi:10.1128/JCM.30.9.2373-2378.1992

21. Jamin N, Miller L, Moncuit J, Fridman WH, Dumas P, Teillaud JL. Chemical heterogeneity in cell death: combined synchrotron IR and fluorescence microscopy studies of single apoptotic and necrotic cells. Biopolymers. 2003;72(5):366-373. doi:10.1002/bip.10435

22. Holman HYN, Martin MC, Blakely EA, Bjornstad K, McKinney WR, Spectroscopic IR. Characteristics of cell cycle and cell death probed by synchrotron radiation based fourier transform IR spectromicroscopy. Biopolymers. 2000;57(6):329-335. doi:10.1002/ 1097-0282(2000)57:6<329::AID-BIP20>3.0.CO;2-2

23. Teli MD, Kale RD. Polyester nanocomposite fibers with improved flame retardancy and thermal stability. Polym Eng Sci. 2012;52 (5):1148-1154. doi:10.1002/pen.22179

24. Kashiwagi T, Gilman JW, Butler KM, Harris RH, Shields JR, Asano A. Flame retardant mechanism of silica gel/silica. Fire Mater. 2000;24(6):277-289. doi:10.1002/1099-1018(200011/12) 24:6<277::AID-FAM746>3.0.CO;2-A

25. Kashiwagia T, Harris RH, Zhang X, et al. Flame retardant mechanism of polyamide 6-clay nanocomposites. Polymer. 2004;45(3):881-891. doi:10.1016/j.polymer.2003.11.036

26. Gawłowski A, Fabia J, Ślusarczyk C, Brzozowska-Stanuch A, Graczyk T, Janicki J. Modification of polyamide 6 fibers with water-glass in bath method. Polimery. 2017;11-12(11/12):861-867. doi:10.14314/polimery.2017.861

27. Holman HYN, Martin MC, McKinney WR. Tracking chemical changes in a live cell: biomedical applications of SR-FTIR spectromicroscopy. Spectroscopy. 2003;17(2-3):139-159. doi: $10.1155 / 2003 / 486940$

28. Barth A. Infrared spectroscopy of proteins. Biochim Biophys Acta. 2007; 1767:1073-1101.

29. Litvinov RI, Faizullin DA, Zuev YF, Weisel JW. The $\alpha$-helix to $\beta$ sheet transition in stretched and compressed hydrated fibrin clots. Biophys J. 2012;103(5):1020-1027. doi:10.1016/j.bpj.2012.07.046

30. Artym J. The role of lactoferrin in the iron metabolism. Part II. Antimicrobial and antiinflammatory effect of lactoferrin by chelation of iron. Postepy Hig Med Dosw. 2010;64:604-616.

31. Gutteridge JM, Quinlan GJ. Antioxidant protection against organic and inorganic oxygen radicals by normal human plasma: the important primary role for iron-binding and iron-oxidising proteins. Biochim Biophys Acta. 1993;1156(2):144-150. doi:10.1016/03044165(93)90129-V

32. Gutteridge JM. Lipid peroxidation and antioxidants as biomarkers of tissue damage. Clin Chem. 1995;41(12):1819-1828. doi:10.1093/ clinchem/41.12.1819 


\section{Publish your work in this journal}

Nanotechnology, Science and Applications is an international, peerreviewed, open access journal that focuses on the science of nanotechnology in a wide range of industrial and academic applications. It is characterized by the rapid reporting across all sectors, including engineering, optics, bio-medicine, cosmetics, textiles, resource sustainability and science. Applied research into nano-materials, particles, nano-structures and fabrication, diagnostics and analytics, drug delivery and toxicology constitute the primary direction of the journal. The manuscript management system is completely online and includes a very quick and fair peer-review system, which is all easy to use. Visit http://www.dovepress.com/testimonials.php to read real quotes from published authors. 